Research Article

\title{
Determinants of Commodity Futures Prices: Decomposition Approach
}

\author{
Emmanuel Antwi (D), ${ }^{1}$ Emmanuel N. Gyamfi ${ }^{D},{ }^{2}$ Kwabena Kyei, ${ }^{1}$ Ryan Gill, ${ }^{3}$ \\ and Anokye M. Adam $\mathbb{D}^{4}$ \\ ${ }^{1}$ University of Venda, Thohoyandou, South Africa \\ ${ }^{2}$ School of Business, Ghana Institute of Management and Public Administration, Accra, Ghana \\ ${ }^{3}$ University of Louisville, Louisville, USA \\ ${ }^{4}$ School of Business, University of Cape Coast, Cape Coast, Ghana \\ Correspondence should be addressed to Emmanuel N. Gyamfi; engyamfi@gimpa.edu.gh
}

Received 22 July 2021; Accepted 3 September 2021; Published 4 October 2021

Academic Editor: Yuxing Li

Copyright (c) 2021 Emmanuel Antwi et al. This is an open access article distributed under the Creative Commons Attribution License, which permits unrestricted use, distribution, and reproduction in any medium, provided the original work is properly cited.

\begin{abstract}
Developing models to analyze time series is a very sophisticated, time-consuming, but interesting experience for researchers. Commodity price component determination is challenging due to remarkable price volatility, uncertainty, and complexity in the futures market. This study aims to determine the components that drive the market price of commodity futures. This study utilized the decomposition methods, empirical mode decomposition (EMD), and variational mode decomposition (VMD), to analyze three commodity futures prices data: corn from agricultural products, crude oil from energy, and gold from industrial metal. We applied these techniques to decompose the daily data of each commodity price from different periods and frequencies into individual intrinsic mode functions for EMD and modes for VMD. We used the hierarchical clustering method and Euclidean distance approach to classify the IMFs and modes into high-frequency, low-frequency, and trend. Next, applying statistical measures, particularly, the Pearson product-moment correlation coefficient, Kendall rank correlation, and Spearman rank correlation coefficient, we observed that the trend and low-frequency parts of the market price are the main drivers of commodity futures markets' price fluctuations. The low-frequencies are caused by special events. In a nutshell, commodity futures prices are affected by economic development rather than short-lived market variations caused by ordinary disequilibrium of supplydemand.
\end{abstract}

\section{Introduction}

Globally, crude oil, corn, and gold futures prices have great influence on worldwide economy. These commodities are prone to price fluctuations and have decisive impact on international economic activities as well as both consumers and producers [1], [2]. Price fluctuation is a primary concern as investors are anticipated to make satisfactory profit from their commodity futures market exchange, and the price studies of crude oil, corn, and gold can supply macroeconomic information to investors to minimize risks of loss and maximize profit. The futures market price determinants of these commodities are not affected by demand-supply only but also influenced by several components such as financial policies, growing economy, exacerbation of market speculation, and special events (eruption of war, outbreak of pandemic, 911 gruesome attacks, and 2008 and 2012 global debt crisis) [3]. The remarkable price volatility in the futures market of crude oil, corn, and gold makes it difficult to develop models to analyze the price movements of the aforementioned commodities. Prudent economic and investment decisionmaking, which can assist investors and policymakers to reduce the danger posed by price swinging, therefore, can only be achieved by accurately analyzing the futures market. 
The United States is the leading consumer of corn in the world. In 2019/2020, the United States consumed about 12.30 billion bushels of corn, followed by China. China consumed about 10.98 billion bushels of corn in the same year. The European Union is the third largest consumers of corn globally [4]. These countries are regarded as the world leading economies, which imply that this agricultural commodity plays significant role in the daily planning of the economy of these three countries. According to the International Energy Agency (IEA) 2019 report, United States and China are the leading consumers of crude oil worldwide, which consumed about 19.4 million barrels per day and 14 million barrels per day, respectively. Gold as a precious metal is used as an indicator to hedge against inflation and measure wealth in the world. It is a metal which is fascinated by everyone and has maintained its value over centuries. Unlike crude oil, gold price is not determined by any organization, but mostly depends on the cost of extraction and how much people are willing to pay for it. Gold is expensive due to the high cost associated with its production and also exceeding popularity and can maintain constant weight all the time, which makes it price rise more often. As stated by the futures price discovery mechanism, these commodities are extremely affected by macroeconomic policies; therefore, they are useful in providing price information to spot markets. Hence, discovering the drivers of these commodities is expected not only to minimize the unreliability and decrease the danger in commodity markets but can also help to make strategic and reliable blueprints for government.

Crude oil, corn, and gold were chosen across the commodity price market to conduct this study, which aimed at identifying the underlying components that drive the futures prices' fluctuations in energy, agriculture, and industrial metal because these commodities are regarded as the most volatile, interactive, and complex in the commodity price market and very sensitive to macroeconomic policies [4]. These commodities play a vital role in the world economy; hence, the futures prices of these commodities market price data are very important for any future development plan since there is strong mutual relationship between price, supply, and demand.

Inspired by the aforementioned reasons, we proposed an enhanced signal detector and EMD and VMD techniques, to decompose price series of crude oil, corn, and gold to establish the components that drive commodity futures spot markets' prices. This paper utilizes EMD and VMD to analyze the components of futures prices of corn (from agricultural commodities section), crude oil (from energies section), and gold (from industrial metals' section). By investigating the components that drive commodity futures prices of these selected items, this research contributes to the existing literature as follows:

(1) We demonstrate that the EMD and VMD can reveal the underlying factors that causes corn, crude oil, and gold markets price fluctuations.

(2) Using Hierarchical Clustering and Euclidean Distance Techniques, the IMFs and modes were grouped into their respective frequencies-high-frequency, low-frequency, and trend components.

(3) Subsequently, different statistical measures were used to evaluate the contribution of each frequency to the net variance of the volatility of crude oil, corn, and gold markets' price fluctuations.

(4) The economic interpretations of these components were categorized as near-term fluctuations, as a result of ordinary disequilibrium of supply-demand, unpredictable special events, and a long-term trend. It can, thus, be concluded that commodity futures prices are driven by economic development since low-frequency and trend are dominant components of commodity prices' series. From these processes, some strategic forecasting approaches are discussed in the conclusion.

The remainder of the paper is divided as follows: in Section 2, we review the relevant studies; we detail the data and introduce the EMD and VMD algorithms in Section 3; we discuss the empirical results in Section 4, where also the derived intrinsic modes by EMD and VMD are presented; Section 5 discusses and concludes our findings, where we also provide some possible explanations for the results and future developments.

\section{Related Studies}

Globally, energy, agricultural, and industrial metal products markets are complex, uncertain, volatile, and interdependent. As a result, crude oil, corn, and gold time series are nonlinear and nonstationary [5]. Therefore, determining the drivers of these commodities are demanding task [6]. Much research has been conducted into the analysis of commodity prices, and the usual methods used can be classified into two groups: data-driven approaches and structure-modeling techniques. Data-driven strategies consist of linear regression models such as autoregressive moving average (ARMA) and autoregressive conditional heteroscedasticity- (ARCH-) type models [7], [8] and nonlinear models such as backpropagation neural network (BPNN) and radial basis function neural network (RBFNN) [9]. The structure approach models profile commodity market prices and then uses schedule supply-demand equilibrium to examine the price volatility [10].

The mechanism of commodity price investigation and the factors that influence it can be modeled using structure models; however, the structure method is strenuous to apply due to the distinctive features of the commodity futures market. For instance, oil supplying is difficult to model because it is dispensed by two independent bodies, namely, the non-OPEC and OPEC nations. The non-OPEC countries have no control over oil prices, while the OPEC ones determine the production levels, using several factors, other than reserved capacity [11], Furthermore, the difficulty in modeling commodity futures prices is also due to the unsteady international market environment. The data-driven approaches have proven to be quite versatile for short-term predictions but do not have meaningful economic 
interpretations, as they cannot justify the inherent forces that cause commodity price movement.

Several studies have cropped up in the literature trying to develop models to study the price fluctuations of commodity futures spot market prices. Studies such as those by Zhu et al. [12], Wang et al. [13], Miao et al. [14], Boubaker and Raza [15], and Wang and Li [16] used singular spectrum analysis (SSA) and wavelet and combined with neural network models such as backpropagation neural network, radial basis function, and wavelet neural network to predict commodity futures prices. They used SSA and wavelet to decompose crude oil, corn, and gold prices series. The experimental results revealed that the neural network models combined with SAA perform better than the benchmark models.

Boubaker and Raza [15] employed the wavelet method to analyze mean and volatility spillovers between oil price and BRICS stock markets at different time intervals. They developed a combined model, VARM-GARCH-cDCC, to examine the effects of spillover on mean and variances of level prices at different time scales. Evidence from the investigation indicates that the information within the oil industry and volatilities have strong influence on oil price and stock market prices but have no effects on the volatilities of other prices. The results also revealed that the proposed VARM-GARCH-cDCC combined with wavelet decomposition predicts the oil price accurately. However, using SAA and wavelet as a data preprocess tool has some drawbacks. SSA and wavelet decompositions extract false cycles forming part of the series since choosing the function basis, and the decomposition levels are subjective. Wavelet is nonadaptive in nature.

An objective data analysis approach, such as empirical mode decomposition (EMD), proposed by Huang et al. [17], and variational mode decomposition (VMD), suggested by Dragomiretskiy and Zosso [18], can be used to address the challenges in modeling and in the absence of meaningful economic interpretations in market price of commodity futures.

EMD is empirical in nature; it is instinctive, straight, and robust data pretreatment technique developed, particularly, for nonlinear and nonstationary data preprocessing. The work of EMD is to break down the data into a discrete number of intrinsic mode functions (IMFs) in such a manner that the data is near periodic based on peculiar characteristics, called the "extrema," which is the length between two sequential local extrema; thus, based on the scale, the meaning of each IMF and the interpretations can be established; for instance, an intrinsic mode associated with financial time series with a scale of three months is considered as a special event or seasonal event. Exploring data's intrinsic modes is very important to understand economic interpretation since data is the only relationship we have with real life.

Researchers have applied EMD in studies on economic and financial data. It has been applied, for example, in modeling agricultural products (Wang et al. [13]; Abadan and Shabri [19]), electricity price (Xiong et al. [20]; An et al. [21]; Crosato et al. [22]), on exchange rates (Lin et al. [23]; Premanode and Toumazou [24]; Plakandaras et al. [25]), gold prices (Jian-Hui and Wei [26]; Hua and Jiang [27]; Owusu Junior et al.[28]), crude oil prices (Meng et al. [29]; Chen et al. [30]; Yu et al. [31]; Zhang et al. [32]; Wu and Huang [33], and on carbon prices (Zhu et al. [12]). Premanode and Toumazou [24] used differential empirical mode decomposition (DEMD) for improving forecasting of exchange rates using the support of vector regression (SVR). The simulation report showed that when DEMD integrated with the SVR model, it was more robust than the state-of-art Markov switching generalized autoregressive conditional heteroskedasticity (MS-GARCH) and Markov switching regressive (MSR) models.

Korotin et al. [34] used EMD and combined with the Hurst exponent to assess the effects of economic sanctions on ruble exchange rate in Ukraine. They based their argument on the theory of an effective market and reported that there was no direct impact of sanctions on the ruble exchange rate and concluded that the foreign exchange market has a long memory.

Zhu et al. [35] proposed EMD and combined with the counterfactual analysis to estimate the effects of China's export policy on the price of tin. They used four different kinds of decompositions in their analysis and selected the EMD method as the best decomposition technique. The empirical results revealed that China's export policy has no effect on tin price, but the abolition of export policy brought about an increase in supply of global tin market, such that there was downward trend in the tin prices in the long run, which resulted in the short-term fluctuation in the international tin market, and that market policy and price are effective response of trade policy.

Zhu et al. [36] proposed the EMD method to study the spillover effects between carbon market and electricity market. EMD was applied to decompose carbon and electricity prices into several modes with different frequencies and used conditional value at risk was used to detect the spillover effects between carbon market and electricity market. The experimental results indicate that the spillover effects of carbon market affect electricity market positively, while spillover effects of electricity market affect carbon market negatively. It further revealed that, for high and low frequency modes, the spillover effects of carbon market affect electricity market positive, and vice versa. For the case of intermediate frequency, there exist a negative bidirectional spillover effect between the two markets.

Dragomiretskiy and Zosso [18] introduced the VMD model to improve EMD and EEMD by reducing endpoints' effect and mode mixing. VMD is a nonrecursive and bandwidth-limited optimization signal decomposition method, using the Wiener filtering and Hilbert transform; it can decompose nonlinear and nonstationary time series data. VMD assumes that each mode has a limited bandwidth of center frequency and minimizes the sum of estimated bandwidth of each mode and the sum of each is equal to the observed data; moreover, it is robust to noisy data.

VMD is developed to decompose nonlinear and nonstationary data and has, increasingly, attracted research attention in many fields. For instance, Lahmiri [37] employed VMD as a data preprocessing tool to predict 
intraday stock prices at different frequencies. The study revealed that the VMD combined with other models forecast stock better than single models.

Aneesh et al. [38] studied performance analysis of VMD over empirical wavelet transform (EWT) using six different categories of power for recognition of power quality disturbances. The report on the identification indicated that VMD was superior to EWT in terms of the trait extraction process and identification accuracy. Seo et al. [39] employed VMD to model daily rainfall-runoff, and they reported that VMD models were robust regarding efficiency and effectiveness.

Niu et al. [40] used VMD-LSTM to forecast the stock price index. VMD was proposed to decompose the actual series of stock price into different number of modes, and the result was compared to EMD-based hybrid models. They reported that the VMD-LSTM model improves the forecasting of the stock price index. The combined model outperforms the single models, and predicting precision of VMD-based models was better than the EMD-based models using complexity-invariant distance (CID) as a statistical measure in rating the predictability of the models.

Zhu et al. [5] analyzed the price series and volatility of natural rubber's market using VMD as data preprocessing to decompose the rubber futures series from Shanghai Future Exchange into different modes. A hybrid VMD-BiGRU model was formulated to forecast the short-term rubber futures on the Shanghai Future Exchange. The empirical results revealed that the VMD approach emerged as a robust technique for analyzing natural rubber's market and can detect the hidden factors associated with rubber market price fluctuations. Similarly, Huang and Deng [41] employed VMD to predict the crude oil prices series. VMD was combined with long short-term memory (LSTM) and moving window to form a hybrid model, VMD-LSTM-MW, to forecast monthly and daily crude oil price. They reported that the VMD-LSTM-MW model was superior to a singleenergy based (SE). Jianwei et al. [42] predicted the movement of gold price futures fluctuations by utilizing VMD technique to decompose the original gold price series into different modes. A hybrid model was formulated based on independent component analysis (ICA) and gate recurrent unit neural network (GRUNN) approach, called VMD-ICAGRUNN. The empirical results indicate that the combined method, VMD-ICA-GRUNN, predicts gold price accurately as compared to single benchmark models, such ARIMA, radial basis function neural network (RBFNN), long shortterm memory neural network (LSTM), GRUNN, and ICALSTM. He et al. [43] proposed forecasting models, combined with VMD quantile regression neural network (QRNN), to predict three crude oil markets, the West Taxes Intermediate (WTI), the Brent, and the OPEC markets, and reported that the proposed hybridization approach to forecast oil price volatility market accurately and increasing forecasting ability of QRNN.

It is clear evidence that EMD and VMD framework have been used recently as data processing in predicting commodity market prices. However, none of the studies analyzed the underlying components that drive commodity futures prices, and as a result, this current study proposes two decompositions, EMD and VMD techniques, as a data pretreatment method to identify the underlying factors that causes fluctuations in crude oil, corn, and gold markets. This paper introduces a new signal decomposition technique, VMD and EMD, to decompose crude oil, corn, and gold prices series into several modes and use statistical measures, hierarchical clustering method and Euclidean distance approach, to group the IMFs and the modes into high frequency, low frequency, and trend. The contribution of each component to the volatility of three commodity markets is analyzed. The contribution of each IMF or mode to the total variance of the volatility of crude oil, corn, and gold markets price fluctuations can be established using the Pearson product-moment correlation coefficient, Kendall rank correlation, and Spearman rank correlation coefficient.

\section{Data and Descriptive Statistics}

This part of the study presents the data selection, descriptive statistics of the data, data pretreatment, and experimental procedure. As mentioned in the Section 1, to analyze the drivers of commodity futures prices, this study chose three commodities' prices across the stock market, namely, corn from agricultural products, crude oil from energy, and gold from industrial metal, to conduct this empirical research. Table 1 shows the descriptive statistics of the three commodities, and Figures 1-3 represents the time series plots of corn, crude oil, and gold, respectively.

Daily closing spot market prices from Bloomberg Commodities Index were used in this empirical exercise. Bloomberg Commodities Index, which is considered the standard price for global commodity markets, was used to analyze futures prices of crude oil, corn, and gold in this experiment. We used 1277 observations for the price series of each commodity from May 2016 to April 2021. The data were obtained from http://www.bloomberg.com.

The corn and gold had positive skewness. This suggests the distribution of the two commodities spot market prices has a right tail. The crude oil had negative skewness, which indicates that the spot prices of crude oil have a left tail, as shown in Table 1. The results are confirmed by the minimum and the maximum and the time series plots of the commodity futures prices in Figures 1-3. Kurtosis of 11.98, 4.05, and 2.59 , respectively, indicate that the distribution of daily spot market prices was leptokurtic. The high Jarque-Bera test statistics suggest that the commodity futures prices did not follow a normal distribution. These confirmed the nonnormality and positive skewness of corn and gold and negative skewness of crude oil daily spot market prices of commodity futures prices as revealed by time series plots in Figures 1-3, respectively.

\section{Methods}

4.1. Empirical Mode Decomposition (EMD) Algorithm. The empirical mode decomposition technique was introduced by Huang et al. [17] as a nonlinear and nonstationary historical dataset pretreatment tool. It is a robust and 
TABle 1: Period, sample size, and descriptive statistics of the three commodities' future price series of the three commodities.

\begin{tabular}{lccccccccc}
\hline Commodity & Period & Sample size & Mean & Std. dev. & Skewedness & Kurtosis & Jarque-Bera & Minimum & Maximum \\
\hline Corn & $2016-2021$ & 1277 & 3.80 & 0.58 & 2.69 & 11.98 & 5830.30 & 3.02 & 7.53 \\
Crude oil & $2014-2021$ & 1277 & 52.80 & 10.62 & -0.61 & 4.05 & 137.17 & 10.01 & 76.41 \\
Gold & $2016-2021$ & 1277 & 1429 & 232.89 & 0.99 & 2.59 & 215.66 & 1128 & 2069 \\
\hline
\end{tabular}

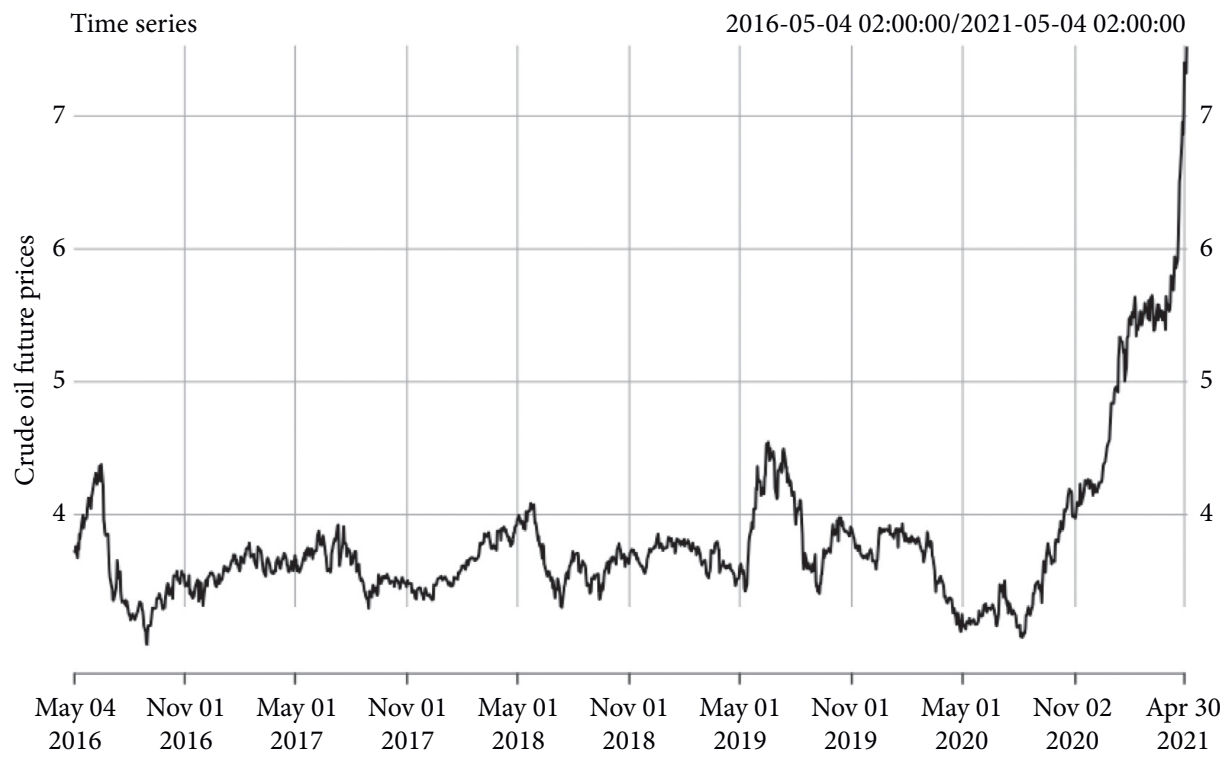

FIGURE 1: Futures prices series of corn (May 2016-April 2021).

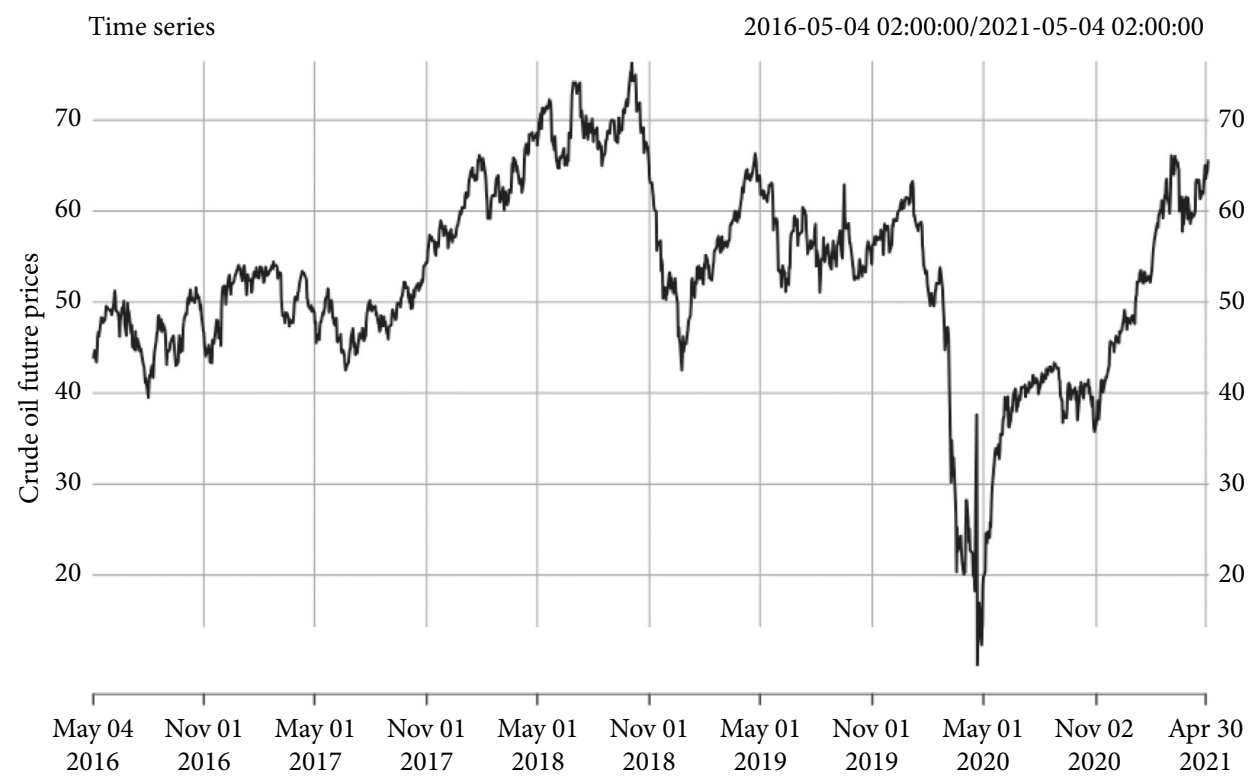

Figure 2: Futures prices series of crude oil (May 2016-April 2021).

systematic decomposition technique used in analyzing nonlinear and nonstationary time series. The EMD addresses full frequency content that cannot be explained by a single Hilbert transform. In analyzing commodity price series within its time domain, some important features may not be uncovered. EMD presumes that analyzing data in its bulk state may have several hidden modes swinging simultaneously. EMD, as a data processing tool, can bring out inherent modes from the actual series, derived from the distinct features of the actual data. EMD can present each inherent mode as an intrinsic mode function (IMF).

We follow Zhu et al. [12] in presenting the EMD algorithm. The EMD approach is operated on the following presumptions: 


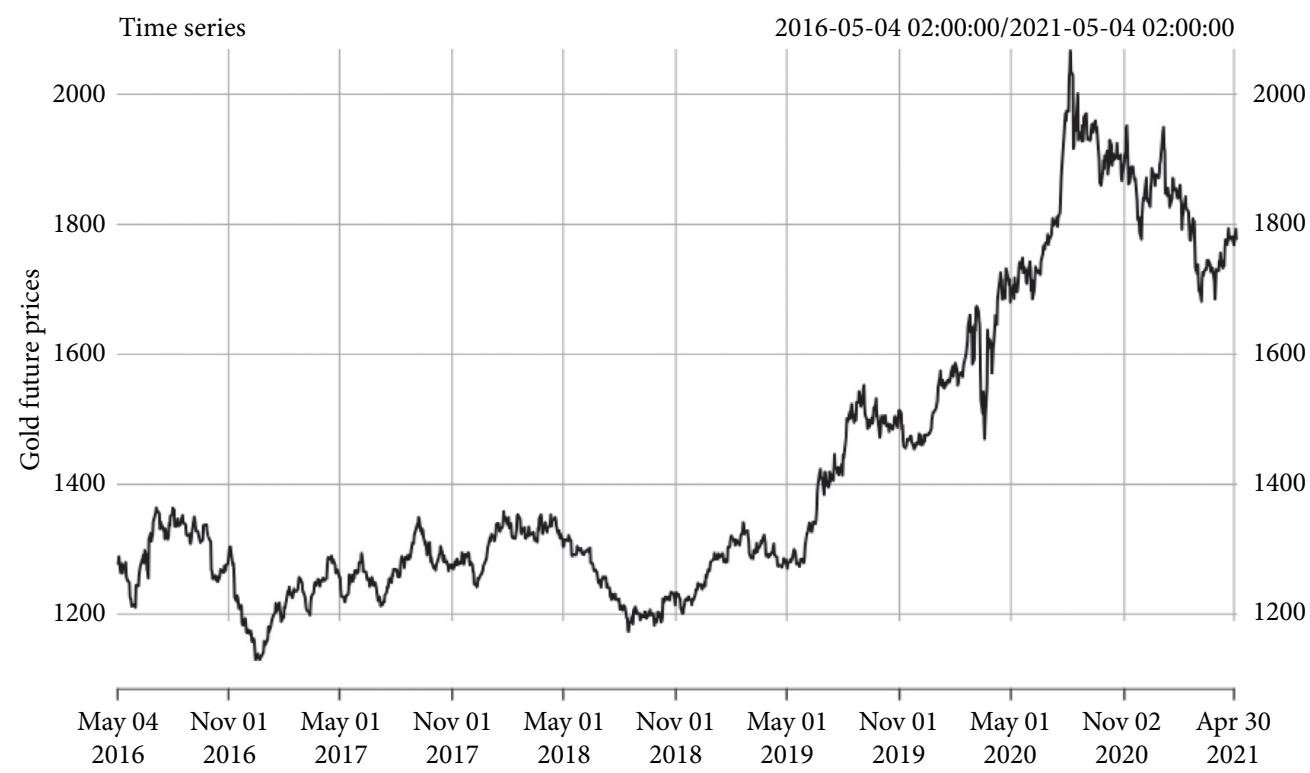

Figure 3: Futures prices series of gold (May 2016-April 2021).

(i) There must be at least one maximum and one minimum in the actual signal

(ii) There must be characteristics' time scale between the extrema

(iii) If there is no extremum in the data but have an inflexion point, then the data can be differentiated once or several times to bring out the extrema

The above assumptions make sure that there is harmony in the IMF and approaching periodic function and put the mean to zero. The following parameters, amplitude, frequency, and mean must be zero to certify that an IMF is a harmonic function. In practice, the act of extracting the IMFs from the data is called the "sifting" process. The EMD method can convert the time series data into a bounded and compact figure of intrinsic functions (IMFs).

The EMD process is as follows:

(a) All the maxima and minima of the commodity prices series were identified and denoted by $v(x)$

(b) Next, we used cubic spline interpolation to produce the upper and lower envelopes, $e_{\min (x)}$ and $e_{\max (x)}$

(c) The point-by-point mean represented by $h(x)$ were estimated from upper and lower envelopes using the following formula:

$$
h(x)=\frac{e_{\min (x)}+e_{\max (x)}}{2} .
$$

(d) The mean was obtained from the series, $v(x)$, and defined the difference of $v(x)$ and $h(x)$ by $d(x)$ :

$$
d(x)=v(x)-h(x) .
$$

(e) We checked the characteristics of $d(x)$

(i) If $d(x)$ is an IMF, we denoted $d(x)$ as ith IMF and replaced $v(x)$ with residual:

$$
r(x)=v(x)-d(x)
$$

The $i$ th IMF is denoted by $c_{i}(x)$, and $c_{i}(x)$ is called its index

(ii) If $d(t)$ was not IMF, it replaced $v(x)$ with $d(x)$

(f) We repeated Steps (a)-(e) till the residuals met some stopping criteria. For details about stopping criteria, see the work of Zhu et al. [12].

Hence, the commodity futures prices $v(x)$ can be written as the sum of IMFs and a residue, mathematically as follows:

$$
v(x)=\sum_{i=1}^{n} c_{i}(x)+r_{n}(x),
$$

where $n$ is the number of IMFs, $r_{n}(x)$ is the final residue, and $c_{i}(x)$ is the $i$ th IMF.

In the extraction of IMFs, $c_{1}$ is the first extracted component and holds the IMF with the first-class scale of the commodity price series. After the extraction, $c_{1}$ is the residue and identified as the element with a longer period variation; thus, EMD filters and groups the IMFs into high-frequency and low-frequency modes. Practically, the grouping of IMFs is based on the algorithm called "fin-to-coarse reconstruction." This study uses the Euclidean distance and hierarchical clustering approaches to classify the IMFs into high and low frequencies.

In general, EMD has the following advantages over other decomposition methods:

(1) EMD can break down any sample size data into simple independent intrinsic mode function

(2) It differs from the wavelet approach because the decomposition depends on the distinct characteristic time scale of the data and allows only extrema in the sifting process; therefore, it is robust, highly efficient, and distinct [44] 
(3) The extracted IMFs through EMD have an instantaneous frequency based on deriving the phase functions such that we can apply the Hilbert transformation to the IMFs

4.2. Variational Mode Decomposition (VMD) Algorithm. Empirical mode decomposition (EMD) has drawbacks, such as mode mixing, noise sensitivity, and sampling. VMD is more robust than EMD in terms of signal decomposition [18]. To overcome the difficulties with EMD, attempts were made at replacing local mean estimation and envelope in EMD [45]. Synchro-squeezed transform (SST) [46], empirical wavelet transforms (EWT) [47], and VMD are different classes of data-driven approaches that aim to extract EMD-like decomposition. VMD is a nonrepeating signal processing method; it is employed to disintegrate real-valued signals into several independent number of band-limited subsignals, called modes $y_{k}$, with specific sparsity characteristics. The extracted modes can be reduced to one center known as "pulsation" $\omega_{t}$, accompanied by the decomposition process. In estimating the bandwidth, we follow the process below:

(1) Apply Hilbert transform to each extracted mode $y_{k}$, to calculate the center frequency spectrum
(2) The calculated center frequency is mixed with the exponential tuned to adjust the mode's frequency spectrum to baseband

(3) Estimate the bandwidth of each mode $y_{k}$, by using the $H^{1}$ Gaussian smoothness of the demodulated signal

Mathematically, a constrained variational problem is formulated as follows:

Let $v(t)$ be the actual signal of the series and $y_{k}$ be the $k$ th of the actual signal; then,

$$
v(t)=\sum_{k=1}^{m} y_{k} .
$$

The constrained variation can be minimized as follows:

$$
\operatorname{Min}\left\{y_{k}\right\},\left\{\omega_{k}\right\}\left\{\sum_{k=1}^{m}\left\|\partial_{t}\left[\left(\delta_{t} \mid \delta(t)+\frac{j}{\lambda t}\right) \otimes y_{k}(t)\right] e^{-j \omega_{k} t}\right\|_{2}^{2}\right\},
$$

where $v(t)$ is the actual signal, $y_{k}$ is the $k$ th element of the actual signal, $\omega_{k}$ is the center frequency of $y_{k}, \delta(t)$ is Dirac distribution, $\otimes$ is convolution operator, $m$ is the number of modes, and $t$ is time script. Considering both penalty term and Lagrangian multiplier, $\lambda$, the above constrain problem can be changed to an unconstrained one as

$$
L\left(\left\{y_{k}\right\},\left\{\omega_{k}\right\}, \lambda\right)=\propto \sum_{k=1}^{m}\left\|\partial_{t}\left[\left(\delta(t)+\frac{1}{\pi t}\right) \otimes y_{k}(t)\right] e^{-j \omega_{k} t}\right\|_{2}^{2}+\left\|v(t)-\sum_{k=1}^{m} y_{k}(t)\right\|_{2}^{2}+\left\langle\lambda(t), v(t)-\sum_{k=1}^{m} y_{k}(t)\right\rangle,
$$

where $\propto$ is the constraint-stabilizing parameter of the data and $L$ is the augmented Lagrangian.

The augmented Lagrangian $L$ can be estimated in equation (7), and it is the associated minimax point in the iterative series. Suboptimization of $L$ and its minimax point can be obtained using the alternate direction method of multipliers (ADMM). The ADMM optimization method presumes that updating the actual signal, $y_{k}$, and center frequency, $\omega_{k}$, in two different directions help to achieve better VMD analysis results. See [18] for a detailed algorithm of ADMM.

The solution for $y_{k}$ and $\omega_{k}$ is mathematically illustrated as follows:

$$
\begin{aligned}
& \hat{y}_{k}^{n+1}=\frac{\widehat{f}(\omega)-\sum_{i=k} \widehat{y}_{i}(\omega)+(\hat{\lambda}(\omega) / 2)}{1+2 \propto\left(\omega-\omega_{k}\right)^{2}}, \\
& \omega_{t}^{n+1}=\frac{\int_{0}^{\infty} \omega\left|y_{k}^{n+1}(\omega)\right|^{2} \mathrm{~d} \omega}{\int_{0}^{\infty}\left|\hat{y}_{t}^{n+1}(\omega)\right|^{2} \mathrm{~d} \omega},
\end{aligned}
$$

where $\hat{f}(\omega), \hat{y}_{i}(\omega), \hat{\lambda}(\omega)$, and $\hat{y}_{k}^{n+1}$ are the Fourier transforms of $v(t), y_{i}(t), \lambda(t)$, and $y_{k}^{n+1}(t)$, respectively.

\section{Empirical Results}

This section concentrates on the detailed description of the empirical results and analysis of IMFs derived from EMD and VMD, respectively.

One of the significant contributions of this study is using two decomposition methods to establish the components of commodity futures prices. We applied EMD and VMD techniques to preprocess each sample data to establish commodity futures price units. The observed data of each commodity futures prices is disintegrated into many IMFs and a residue, RES, using the EMD approach. The IMFs generated by EMD is fixed for any sample data; thus, in the EMD technique, the decomposition components for a given data cannot be changed manually. The EMD approach is illustrated in Figure 4.

Unlike EMD, with the VMD technique, the number of modes can be changed to suit the experimental needs. In this research, many tests were carried out to select the optimal number of decompositions for each price series. Figure 5 illustrates the VMD process. 


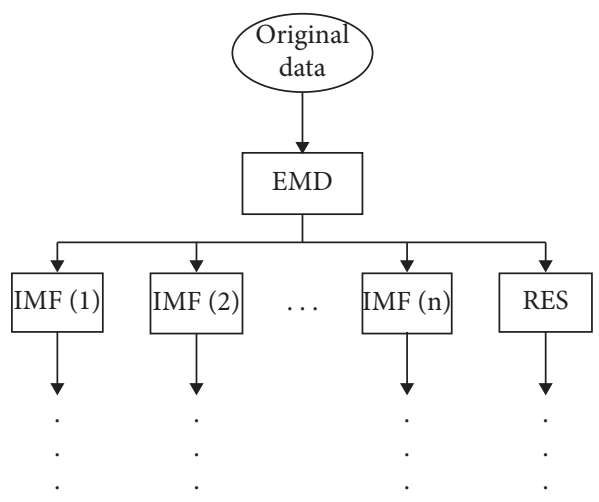

FIgure 4: EMD decomposition process.

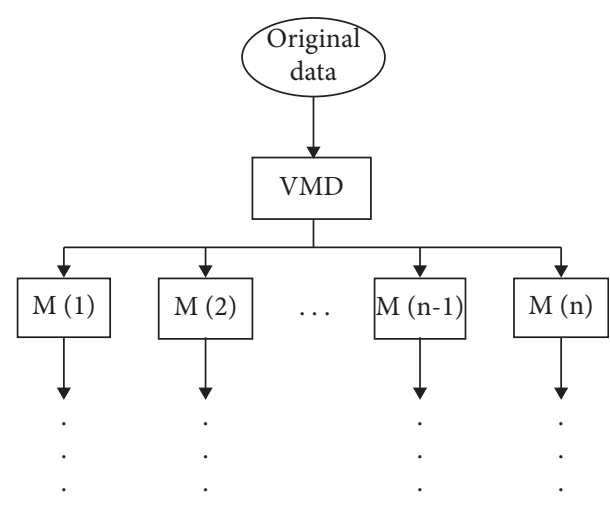

FIgURE 5: VMD decomposition process.

5.1. Decomposition Results and Analysis. This section presents the decomposition results of corn, crude oil, and gold using the EMD and VMD processes.

5.1.1. Decomposition Results of Corn. For corn futures using the EMD method, the sifting processes automatically produced 7 IMFs and one residue, defined as IMF1, IMF2, ..., IMF7. Figure 6 illustrates all the IMFs and the residue of corn futures. The IMFs arranged itself automatically from high frequency to low frequency, and the last one represents the residue in each case. In other words, the IMFs were arranged in order of magnitude. These decompositions represent the price swinging known as a "trend" and market fluctuations, caused by demand-supply and random events, respectively.

Similarly, we applied the VMD technique to decompose the corn price series into eight bind-limit signals, called modes; the decomposition results are shown in Figure 7. The modes were arranged in order of amplitude, thus, the from low-frequency mode to high-frequency mode. We compared eight different decomposition modes, namely, M1, M2, .., M8, respectively.

5.1.2. Statistics of IMF of Corn Derived through EMD Method. The IMFs were analyzed using the following measures: the mean period of each extracted IMF, the correlation between each IMF and the actual price, the variance, and the variance percentage of each IMF. The statistical values of the IMFs and modes of the two decomposition methods of the price data series are presented in Tables 2 and 3, respectively.

The mean period is obtained by dividing the overall data points by the extrema for each decomposed IMF since the frequency and the amplitude of an IMF keep on changing as time goes by; hence, the periods are not static. We used the three correlation coefficients, namely, the Pearson product-moment correlation coefficient, Kendall rank correlation coefficient, and the Spearman correlation coefficient, to estimate the correlation between the IMFs and the actual price. The contribution of each IMF to the total variance of the actual price can be explained by summing up the variances and finding the percentage of the variance since these IMFs do not become dependent on each other. According to Peel et al. [48], the observed variance, the variances of IMFs, and the residue may differ when added up; this is a result of rounding-off during calculations, the irregularity in the actual data series, and the introduction of variance. It can be observed that there are a positive $57.245 \%$ and a negative $28.157 \%$ differences, as seen in Tables 2 and 4, respectively.

For the decomposition of corn futures prices' series, the original data series, the leading mode was not any IMF but the residue with the mean period of 425.667 and contributed more than $41 \%$ of the total variability of corn futures prices. It had the highest correlation coefficient with the observed price of $0.61478,0.10777$, and 0.16794 , respectively, and is known for the long-term deterministic trend [17]. The next significant mode was IMF7, which contributed more than $32 \%$ of the total variation of the corn futures prices, with a correlation coefficient between the observed price of $0.54986,0.36244$, and 0.51175 for Pearson, Kendall, and Spearman in that order.

The combined variance of the residue and IMF7 accounted for more than $73 \%$ of the total variance of corn future price volatility. The third important mode was the IMF6, with a correlation coefficient between the observed price of $0.06365,0.02319$, and 0.03523 for Pearson, Kendall, and Spearman, respectively, as shown in Table 2, with a variance contribution of more than $18 \%$ of the future price of corn. The IMF5 accounted for $3.823 \%$ of the variability of corn future price. The IMF4 and IMF3 contributed $2.23 \%$ and $1.076 \%$ of the total variance of corn future price, respectively. The IMF1 and IMF2 accounted for less than $1 \%$ of the variance of the corn future price series.

5.1.3. Statistics of Mode of Corn Derived through VMD Method. Similarly, the decomposition of corn future price series data using VMD produced eight modes, as shown in Figure 7 . The aggregate represents the signal of the observed data. It can be deduced from Table 4 that the leading mode of the actual price was M2, which contributed $50.56 \%$ overall variance of corn future price. Next was M1, with a mean period of 13.165 , which accounted for more than $40 \%$ of the net variability of the actual price data. Besides M1 and M2, 

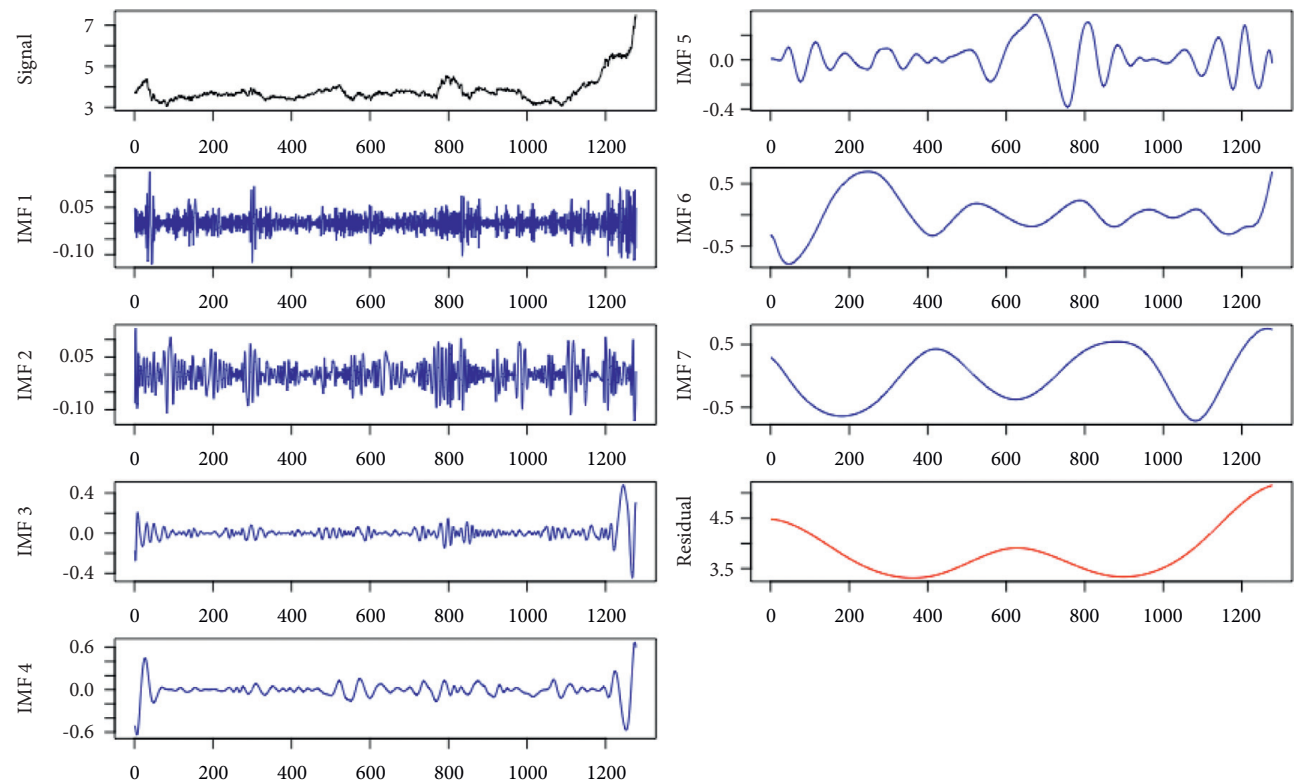

Figure 6: Empirical mode decomposition (EMD) curves for daily corn price series (May 2016-April 2021).

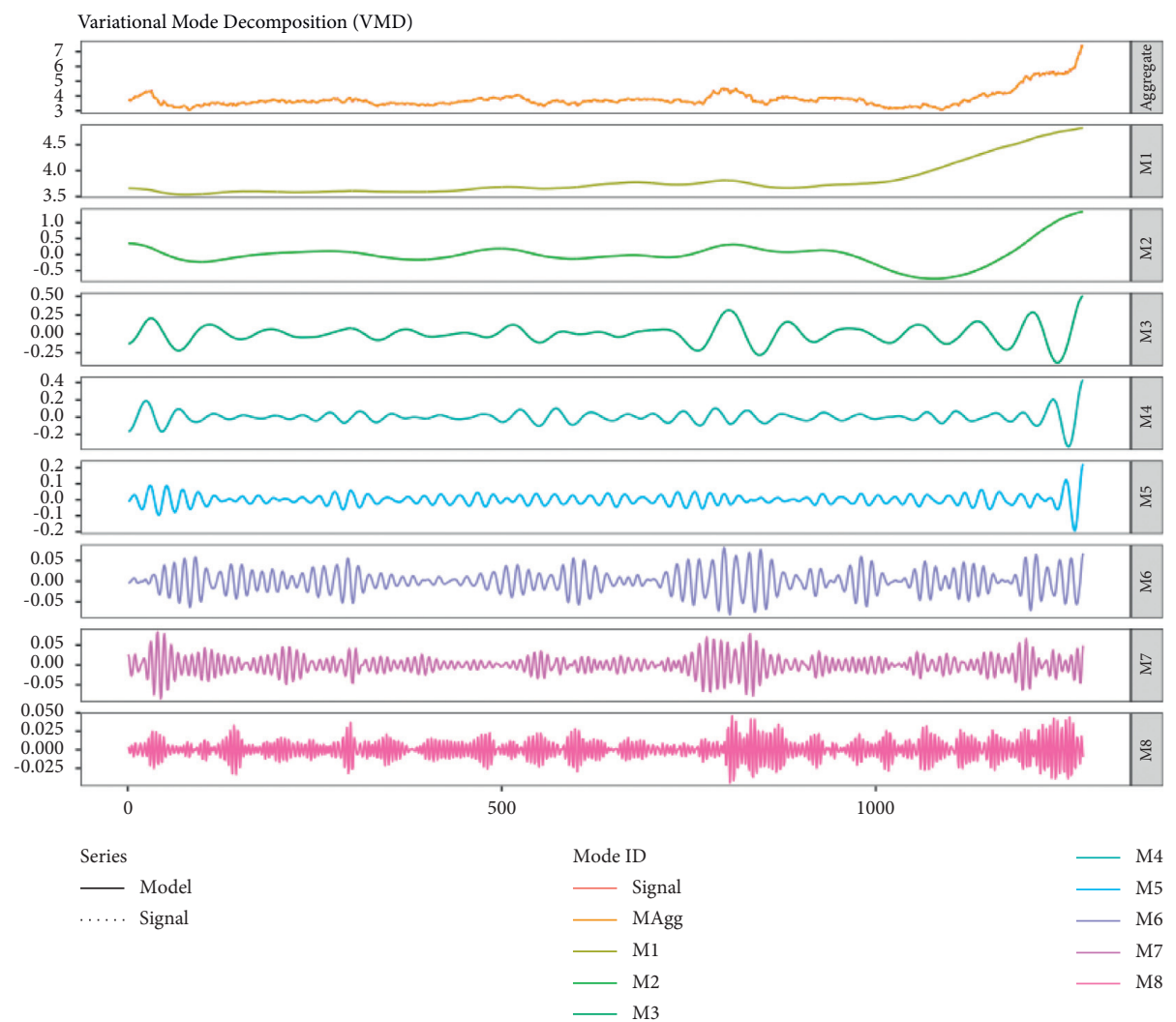

FIgURE 7: Variational mode decomposition (VMD) curves for daily corn price series (May 2016-April 2021).

M3, with a mean period of 38.697 , contributed more than $5 \%$ of the variability of corn future price. For M4, M5, M6, M7, and $\mathrm{M} 8$, the values of correlation coefficients were very low. These modes (M4-M8) contributed 1.765\%, 0.436\%, $0.286 \%, 0.187 \%$, and $0.066 \%$, respectively, of the variability of the observed data.
5.1.4. Constitution of Corn Futures Prices. In addition, following Zhu et al. [12], we used Euclidean distance between pairs of any two IMFs or modes or between an IMF or mode and the residue and hierarchical clustering approach to group the IMFs and the modes into three components. The clustering results are presented in Figure 8. An IMF was 
TABLE 2: Measures of IMFs and residue obtained through EMD of daily price series of corn (May 2016-April 2021): correlation is significant at the level of 0.05 (2-tailed).

\begin{tabular}{|c|c|c|c|c|c|c|c|}
\hline & $\begin{array}{l}\text { Mean } \\
\text { period }\end{array}$ & $\begin{array}{l}\text { Pearson } \\
\text { correlation }\end{array}$ & $\begin{array}{l}\text { Kendall } \\
\text { correlation }\end{array}$ & $\begin{array}{l}\text { Spearman } \\
\text { correlation }\end{array}$ & Variance & $\begin{array}{l}\text { Variance as of } \\
\text { observed (\%) }\end{array}$ & $\begin{array}{c}\text { Variance as \% of } \\
\sum \text { IMFs + residual (\%) }\end{array}$ \\
\hline $\begin{array}{l}\text { Observed } \\
\text { series }\end{array}$ & 2.02377 & & & & 0.33526 & & \\
\hline IMF1 & 1.65415 & 0.03033 & 0.05804 & 0.08160 & 0.00103 & 0.30722 & 0.19538 \\
\hline IMF2 & 3.85801 & 0.01557 & 0.05546 & 0.08244 & 0.00132 & 0.39372 & 0.25039 \\
\hline IMF3 & 8.03145 & 0.18821 & 0.08422 & 0.11590 & 0.00567 & 1.69122 & 1.07553 \\
\hline IMF4 & 17.98592 & 0.13127 & 0.16079 & 0.22557 & 0.01488 & 4.43835 & 2.82257 \\
\hline IMF5 & 38.69697 & 0.10200 & 0.19915 & 0.28984 & 0.01821 & 5.43161 & 3.45423 \\
\hline IMF6 & 116.09091 & 0.06365 & 0.02319 & 0.03523 & 0.09837 & 29.34141 & 18.65966 \\
\hline IMF7 & 212.83333 & 0.54986 & 0.36244 & 0.51175 & 0.16983 & 50.65621 & 32.21480 \\
\hline Residue & 425.66667 & 0.61478 & 0.10777 & 0.16794 & 0.21787 & 64.98538 & 41.32744 \\
\hline Sum & & & & & & 157.245 & 100 \\
\hline
\end{tabular}

TABLE 3: Correlation and variance of components obtained from the IMFs of EMD for daily price series of corn (May 2016-April 2021): correlation is significant at the level of 0.05 (2-tailed).

\begin{tabular}{lccccccc}
\hline & $\begin{array}{c}\text { Mean } \\
\text { period }\end{array}$ & $\begin{array}{c}\text { Pearson } \\
\text { correlation }\end{array}$ & $\begin{array}{c}\text { Kendall } \\
\text { correlation }\end{array}$ & $\begin{array}{c}\text { Spearman } \\
\text { correlation }\end{array}$ & Variance & $\begin{array}{c}\text { Variance as of } \\
\text { observed (\%) }\end{array}$ & $\begin{array}{c}\text { Variance as \% of } \\
\text { IMFs + residual (\%) }\end{array}$ \\
\hline $\begin{array}{l}\text { Observed } \\
\text { series }\end{array}$ & 2.02377 & & & & 0.33526 & & 45.58662 \\
\hline $\begin{array}{l}\text { High } \\
\text { frequency }\end{array}$ & 55.52174 & 0.56739 & 0.39879 & 0.54449 & 0.21369 & 63.73859 & 8.02763 \\
\hline $\begin{array}{l}\text { Low } \\
\text { frequency }\end{array}$ & 32.74359 & 0.15351 & 0.26932 & 0.37196 & 0.03763 & 11.22412 & 46.47834 \\
\hline Trend & 425.66667 & 0.61478 & 0.10777 & 0.16794 & 0.21787 & 64.98538 & 100 \\
\hline Sum & & & & & & 139.94809 & \\
\hline
\end{tabular}

TABLE 4: Correlation and variance of components obtained from modes of VMD for daily price series of corn (May 2016-April 2021): correlation is significant at the level of 0.05 (2-tailed).

\begin{tabular}{lccccccc}
\hline & $\begin{array}{c}\text { Mean } \\
\text { period }\end{array}$ & $\begin{array}{c}\text { Pearson } \\
\text { correlation }\end{array}$ & $\begin{array}{c}\text { Kendall } \\
\text { correlation }\end{array}$ & $\begin{array}{c}\text { Spearman } \\
\text { correlation }\end{array}$ & Variance & $\begin{array}{c}\text { Variance as of } \\
\text { observed (\%) }\end{array}$ & $\begin{array}{c}\text { Variance as \% of } \\
\sum \text { IMFs + residual (\%) }\end{array}$ \\
\hline $\begin{array}{l}\text { Observed } \\
\text { series }\end{array}$ & 2.02377 & & & & 0.33526 & & \\
M1 & 13.16495 & 0.7698 & 0.34161 & 0.44076 & 0.09867 & 29.43089 & 40.96571 \\
M2 & 51.08000 & 0.81506 & 0.56521 & 0.72165 & 0.12177 & 36.32106 & 50.55634 \\
M3 & 38.69697 & 0.27415 & 0.25665 & 0.33405 & 0.01382 & 4.12217 & 5.73777 \\
M4 & 22.40351 & 0.17083 & 0.14986 & 0.20856 & 0.00425 & 1.26767 & 1.76451 \\
M5 & 10.91453 & 0.09350 & 0.08122 & 0.11630 & 0.00105 & 0.31319 & 0.43594 \\
M6 & 7.38150 & 0.07210 & 0.07910 & 0.11401 & 0.00069 & 0.20581 & 0.28647 \\
M7 & 4.72963 & 0.05670 & 0.06294 & 0.08949 & 0.00045 & 0.13422 & 0.18683 \\
M8 & 2.63299 & 0.03922 & 0.04783 & 0.06865 & 0.00016 & 0.04772 & 0.06643 \\
Sum & & & & & & & 71.843 \\
\hline
\end{tabular}

classified as a high-frequency component when the Euclidean distance was less than 10. An IMF was categorized as a low-frequency component when the Euclidean distance was between 10 and 20. The Euclidean distance of more than 20 was considered a trend component. Table 3 and Figure 9 presented the three components and their statistical measures as derived from EMD.

Following the above definition, IMF1, IMF2, IMF3, IMF6, and IMF7 formed the high-frequency components of EMD decomposition, while IMF4 and IMF5 correspond to the low-frequency part of the corn futures price series. Each component has a unique feature and economic interpretation-the low-frequency and the high-frequency components represent special events and short-term market price fluctuations, respectively. The residue changes gradually around the long-term mean, as mentioned in Section 2, and corresponds to the long-term corn futures price trend.

For VMD, unlike EMD, the decompositions are arranged from the low-frequency mode to high-frequency mode. M6-M8, with a short amplitude, represents the highfrequency component of corn price series and accounts for short-term market fluctuations. M2-M5 constitutes the lowfrequency part of corn future price from May 4, 2016, to April 30, 2021, and represents the special events under study, 


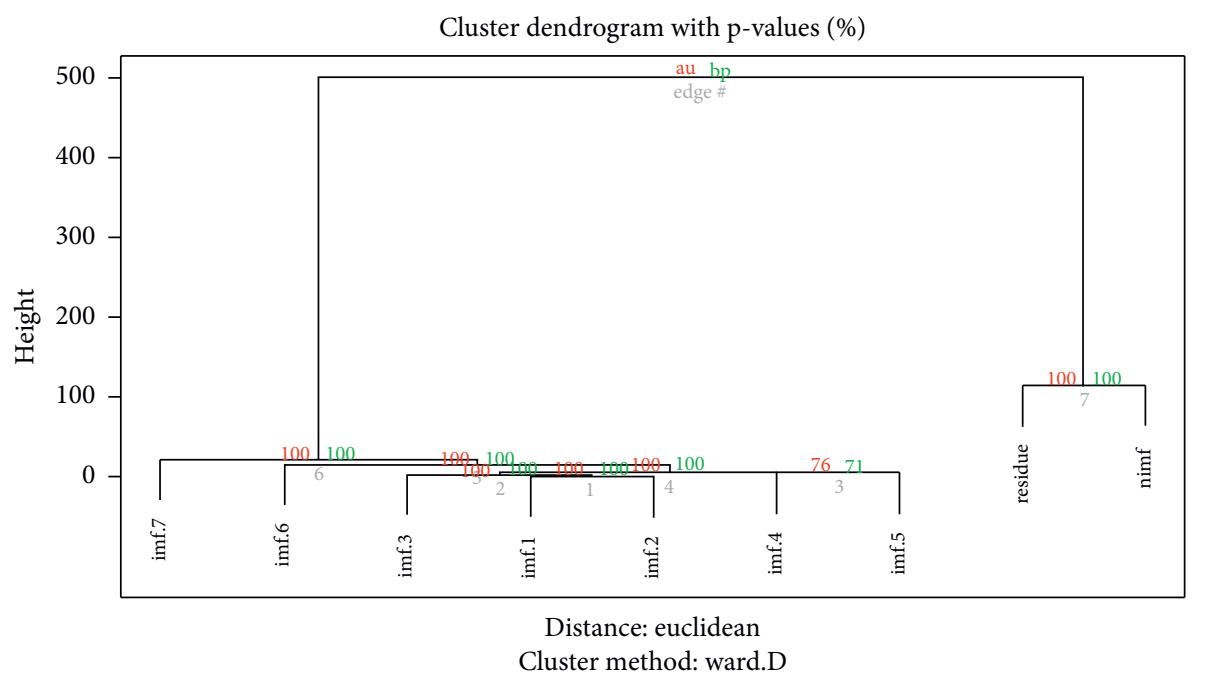

FIgURE 8: Hierarchical clustering diagram obtained for the IMFs and residue through EMD.

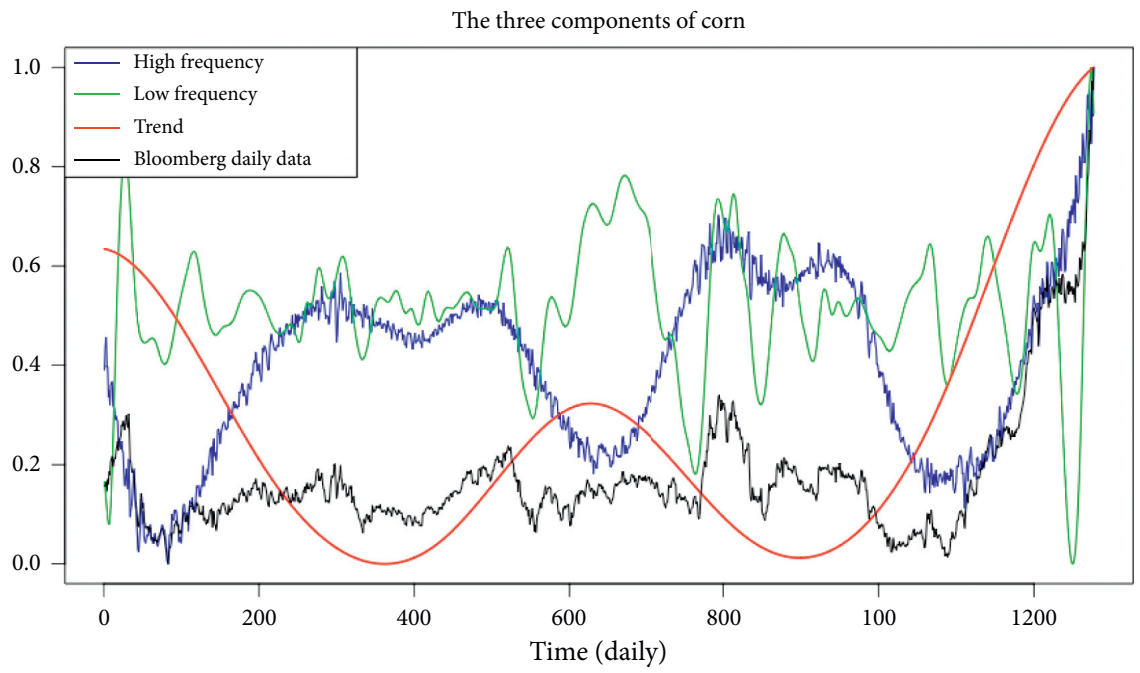

Figure 9: The three components of the Bloomberg daily data of corn (May 2016-April 2021) through EMD.

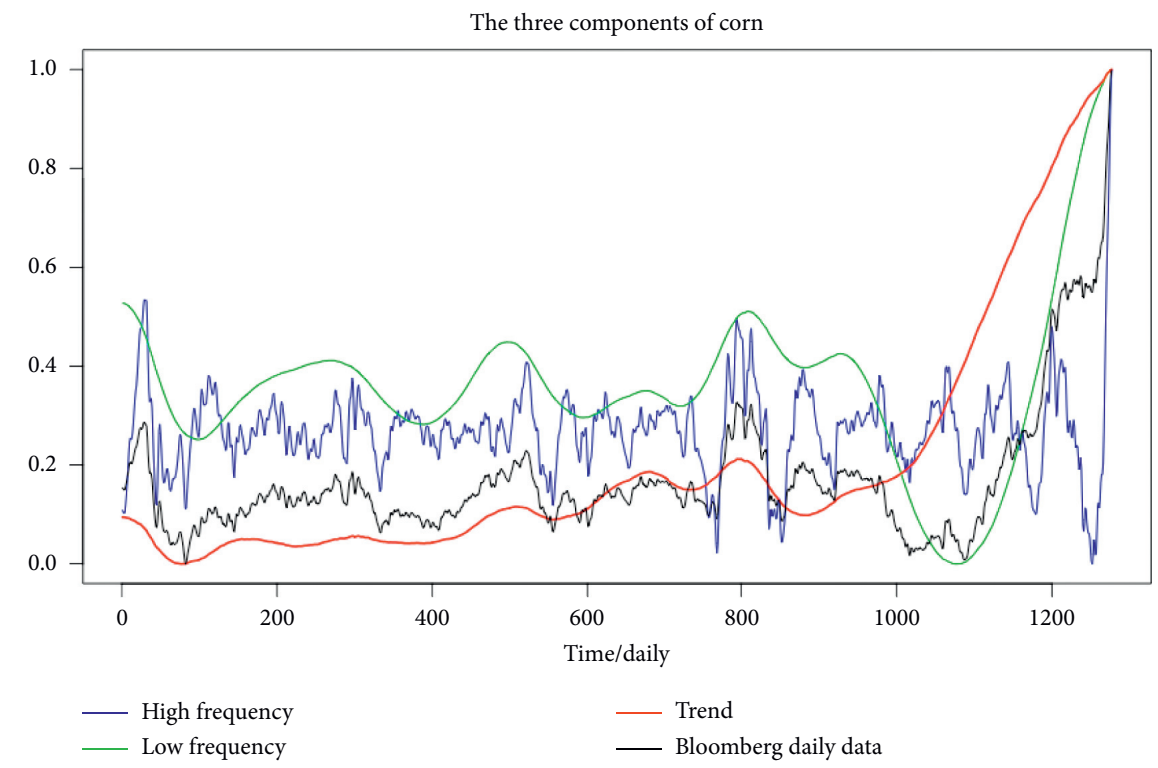

Figure 10: The three components of the Bloomberg daily data of corn (May 2016-April 2021) through VMD. 
TABLE 5: Correlation and variance of components obtained from modes of VMD for daily price series of corn (May 2016-April 2021): correlation is significant at the level of 0.05 (2-tailed).

\begin{tabular}{|c|c|c|c|c|c|c|c|}
\hline & $\begin{array}{l}\text { Mean } \\
\text { period }\end{array}$ & $\begin{array}{c}\text { Pearson } \\
\text { correlation }\end{array}$ & $\begin{array}{c}\text { Kendall } \\
\text { correlation }\end{array}$ & $\begin{array}{c}\text { Spearman } \\
\text { correlation }\end{array}$ & Variance & $\begin{array}{l}\text { Variance as of } \\
\text { observed }(\%)\end{array}$ & $\begin{array}{c}\text { Variance as \% of } \\
\sum \mathrm{Ms}+\text { residual }(\%)\end{array}$ \\
\hline $\begin{array}{l}\text { Observed } \\
\text { series }\end{array}$ & 2.02377 & & & & 0.33526 & & \\
\hline $\begin{array}{l}\text { High } \\
\text { frequency }\end{array}$ & 4.76493 & 0.09428 & 0.10471 & 0.15044 & 0.00145 & 0.43250 & 0.58086 \\
\hline $\begin{array}{l}\text { Low } \\
\text { frequency }\end{array}$ & 63.85000 & 0.85557 & 0.66760 & 0.78770 & 0.14951 & 44.5952 & 59.89264 \\
\hline Trend & 13.16495 & 0.76976 & 0.34161 & 0.44076 & 0.09867 & 29.43089 & 39.52650 \\
\hline Sum & & & & & & 74.45863 & 100.000 \\
\hline
\end{tabular}

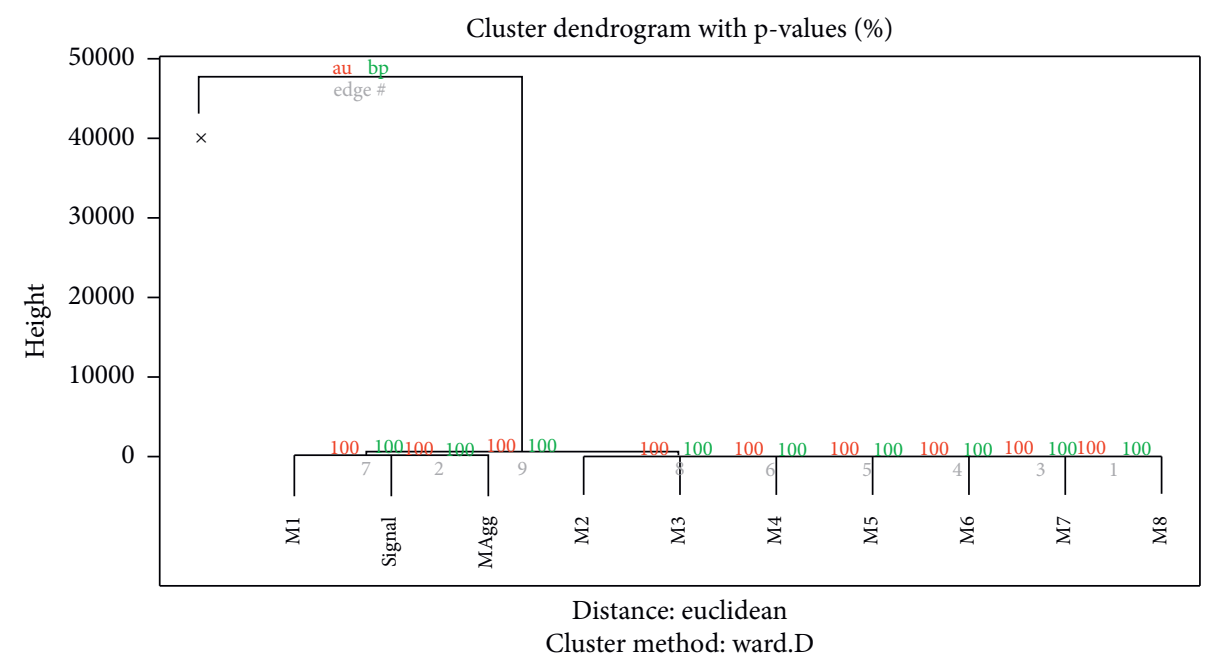

FIGURE 11: Hierarchical clustering obtained for the modes and residue through VMD.

while M1 represents the long-term trend of the corn future price. A plot of the extracted components and their statistical measures through VMD are presented in Figure 10 and Table 5. The classification of the modes using Euclidean distance is presented in Figure 11.

5.1.5. Trend of Corn Futures Prices. Trend accounted for $46.478 \%$ and $39.527 \%$ of the total variability of corn future price in terms of EMD and VMD, respectively. It had the highest correlation coefficient with the observed price of $0.244,0.306$, and 0.410 and $0.703,0.616$, and 0.819 in terms of Pearson, Kendall, and Spearman, respectively, for EMD and VMD. This indicates that trend is an inevitable factor in determining corn future price eventually, as shown in $\mathrm{Ta}$ bles 3 and 5 . The persisting increase in the price of corn is due to worldwide economic evolution; therefore, by comparing the trend with the actual series of corn, it can be deduced that, occasionally, corn future price fluctuates due to unpredictable special events, such pest invasion, adverse weather conditions, and diseases, but reverse to the trend after the factor that triggered the event is controlled.

5.1.6. Effects of Special Events on Corn Price. The IMF6 and M2 from EMD and VMD represent the low-frequency components of corn futures prices, respectively, as shown in Figures 8 and 11. It can be seen from Figures 6 and 7 that the low frequencies are nonlinear and long-term trend. The low frequency contributed $8.028 \%$ and $59.893 \%$ of the total variance of corn futures prices in terms of EMD and VMD, respectively, as presented in Tables 3 and 5. These low frequencies correspond to significant events, such as bad weather, diseases, and pest invasion, which have significant impact on corn price. Based on the mean period of these modes, the shortest impact period is more than one month for the case of EMD and more than 2 months for VMD. It implies that it takes the market some time to eradicate these special events, and the duration may last for a while, looking at the mean period of these special events.

Furthermore, the amplitudes of some of the data points were more than $\$ 5$, which suggests that some special events have a severe consequence on corn futures market prices. Large price fluctuations in corn futures occur in the medium term, due to such significant events. The normal market fluctuation takes place at a high frequency, and the trend changes gradually. We can measure the effectiveness of every significant event as low frequency and separate from the main price; hence, these results can be used in predicting any significant impact from the upcoming event of the same nature. 
5.1.7. Effects of Ordinary Market Disequilibrium on Corn Price. Apart from the trend and the effect of significant events, corn futures prices are also affected by speculation. High frequency occurs as a result of random events, such as speculations within commodity market, financial policies, trade wars, and great events, such as outbreak of pandemic. The effect of these speculations can be classified as high frequency and accounted for more than $45.587 \%$ and $0.581 \%$ of the total variance of corn price in terms of EMD and VMD, respectively. The effects of ordinary market speculation are sometimes called "market disequilibrium" and consist of events with short-term impact on corn futures prices. The word, short term, is used to describe these effects since the data used in this research is daily. The disequilibrium of supply-demand as a normal market fluctuation has a serious impact on corn price as when these events persistently occur, they become one of the main drivers for pushing corn prices up. We can ignore the normal market fluctuations in the long-term trend forecasting; however, they are very crucial for short prediction. Thus, \$386.75/ton of corn in April 2021 can be explicitly explained as a $\$ 106.81$ trend price, $\$ 242.56$ special event price, and an ordinary market fluctuation price of $\$ 37.38$ through the VMD method.

5.1.8. Crude Oil Decomposition Results. Similarly, the price series of crude oil was decomposed using EMD and VMD methods, and the decomposition curves are shown in Figures 12 and 13, respectively. The EMD method decomposed the crude oil data into eight IMFs, called IMF1-IMF8, and one residue, defined as RES, as shown in Figure 12. The VMD approach produced eight modes, and the decomposition result is illustrated in Figure 13.

\subsubsection{Statistics of IMF of Crude Oil Derived through EMD} Method. In analyzing the IMFs derived from EMD of crude oil price series, we again followed Zhang et al. [32] by using the same parameters as that of corn to estimate each IMF contribution to the variability of crude oil price series. The mode which accounted most for the variance of the observed data was IMF8. It contributed more than $37 \%$ of the total variability with the mean period of 319.250 and the correlation coefficients between the observed data was $0.615,0.426$, and 0.604 in terms of Pearson, Kendall, and Spearman, respectively, as shown in Table 6. The IMF7 contributed more than $32 \%$ of the observed data's variability, and the correlation coefficients between the observed data was $0.498,0.315$, and 0.471 for Pearson, Kendall, and Spearman. The two most important IMFs-IMF8 and IMF7-contributed more than $69 \%$ of the crude oil price variance. The IMF5 and IMF6 accounted for $6.079 \%$ and $8.647 \%$ of the variance of crude oil price series, respectively. The remaining IMFs did not contribute much to the original price series variance, indicating that the effect of these IMFs on the crude oil price is minimal.
5.1.10. Statistics of Mode of Crude Oil Derived through VMD Method. Once more, we based our analysis of the modes derived from VMD on the following parameters: a mean period of each mode, the correlation between each mode and the observed data, the variance, and the variance percentage of each mode. Table7 presents the statistics of the modes produced by the VMD method.

The M1 emerged as the dominant mode, with correlation coefficients of $0.731,0.607$, and 0.778 between the mode and the observed data regarding the Pearson, Kendall, and Spearman correlation coefficients, and contributed more than $42 \%$ of the entire variance of the actual prices data. The M1 also exhibits a long cycle and continuously increased the trend, and the observed price series also followed the same pattern. The next important mode was M2 which caused more than $39 \%$ of the crude oil price volatility. The combined impact of M1 and M2 constituted $81.44 \%$ of the overall variance of the crude oil price series. The M3 and M4 contributed $15.42 \%$ and $1.72 \%$, respectively, of the variance of crude oil price. On the contrary, the M5-M8 exhibited small correlation coefficients with the actual data and accounted for less than $2 \%$ of the net variability of crude oil price, suggesting that their impact on the futures prices of crude oil is insignificant.

5.1.11. Constitution of Crude Oil Price Series. Similarly, we grouped the IMFs of crude oil price series into their respective components using hierarchical clustering and the Euclidean distance techniques. The IMF1-IMF4 were classified as a high-frequency component of EMD decomposition, while IMF5-IMF8 represented the low-frequency component of the crude oil price, as shown in Figure 14. These components have unique features and economic meaning-the residue with long-term mean is classified as the trend component of crude oil futures prices, while the low-frequency part represents the effect of significant events. The high-frequency component is identified by its short amplitudes and constitutes shocks caused by short-lived market fluctuations.

For the VMD approach, M4-M8 form the high-frequency part of the oil price series and constitute short-term market fluctuations. The M2 and M3 correspond to the low-frequency component of the oil series from 2016 to 2021, representing the significant events of the period under consideration. The M1 represents the long-term trend of the crude oil futures prices, as shown in Table 8 and Figure 15.

5.1.12. The Trend of Crude Oil Futures Prices. The second deterministic factor of crude oil prices is the trend; it accounted for more than $10 \%$ of the variability of crude oil future price volatility through EMD, as shown in Table 9. This was confirmed by the VMD process, and the trend was still the second determinant of the crude oil price fluctuations, contributed more than $27 \%$ of the total variability of crude oil futures, and holds a correlation coefficient of 0.731 , 0.607 , and 0.778 between the original price series for Pearson, Kendall, and Spearman, suggesting that the trend 

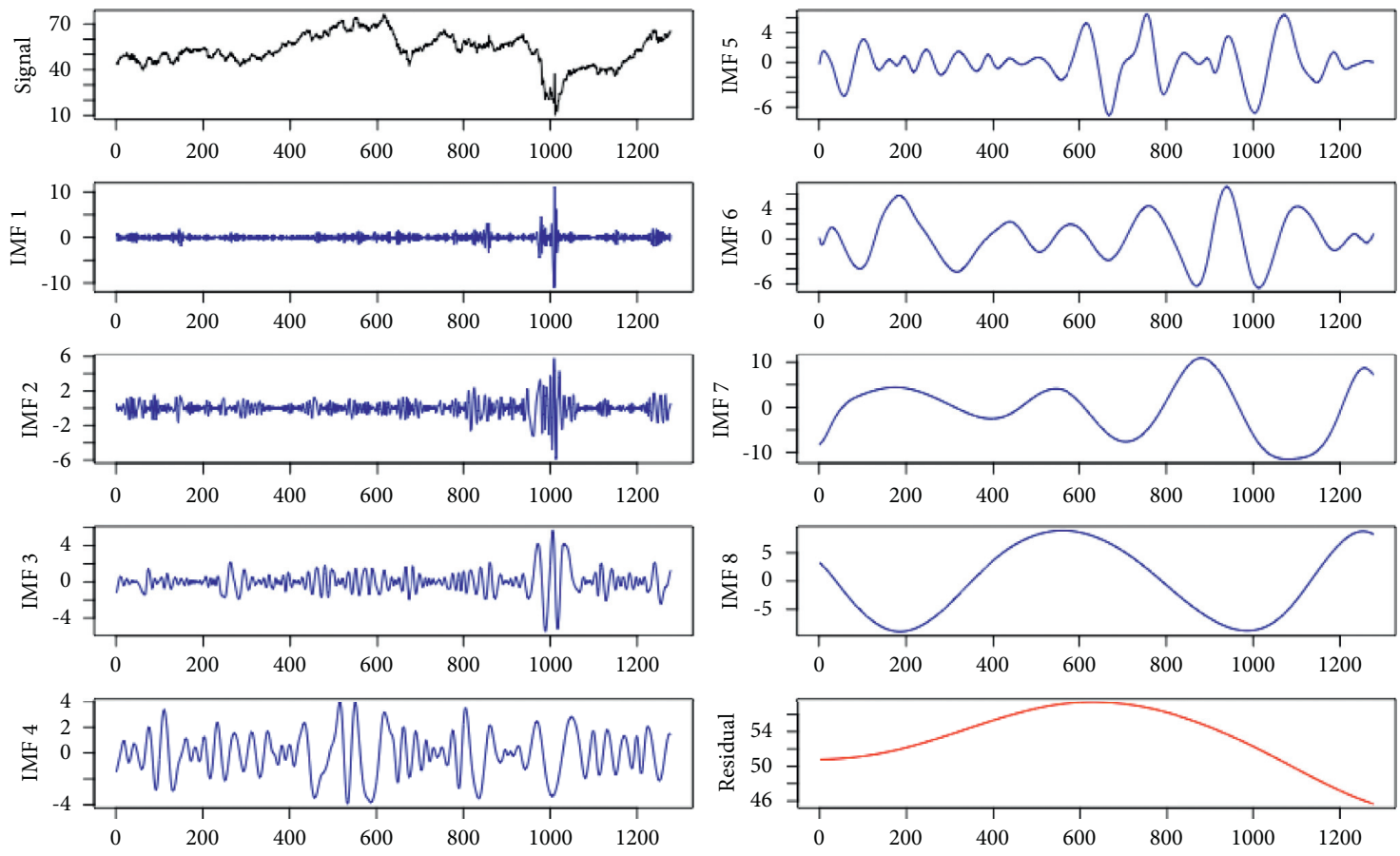

FIgURE 12: Empirical mode decomposition curves of daily crude oil price series (May 2016-April 2021).

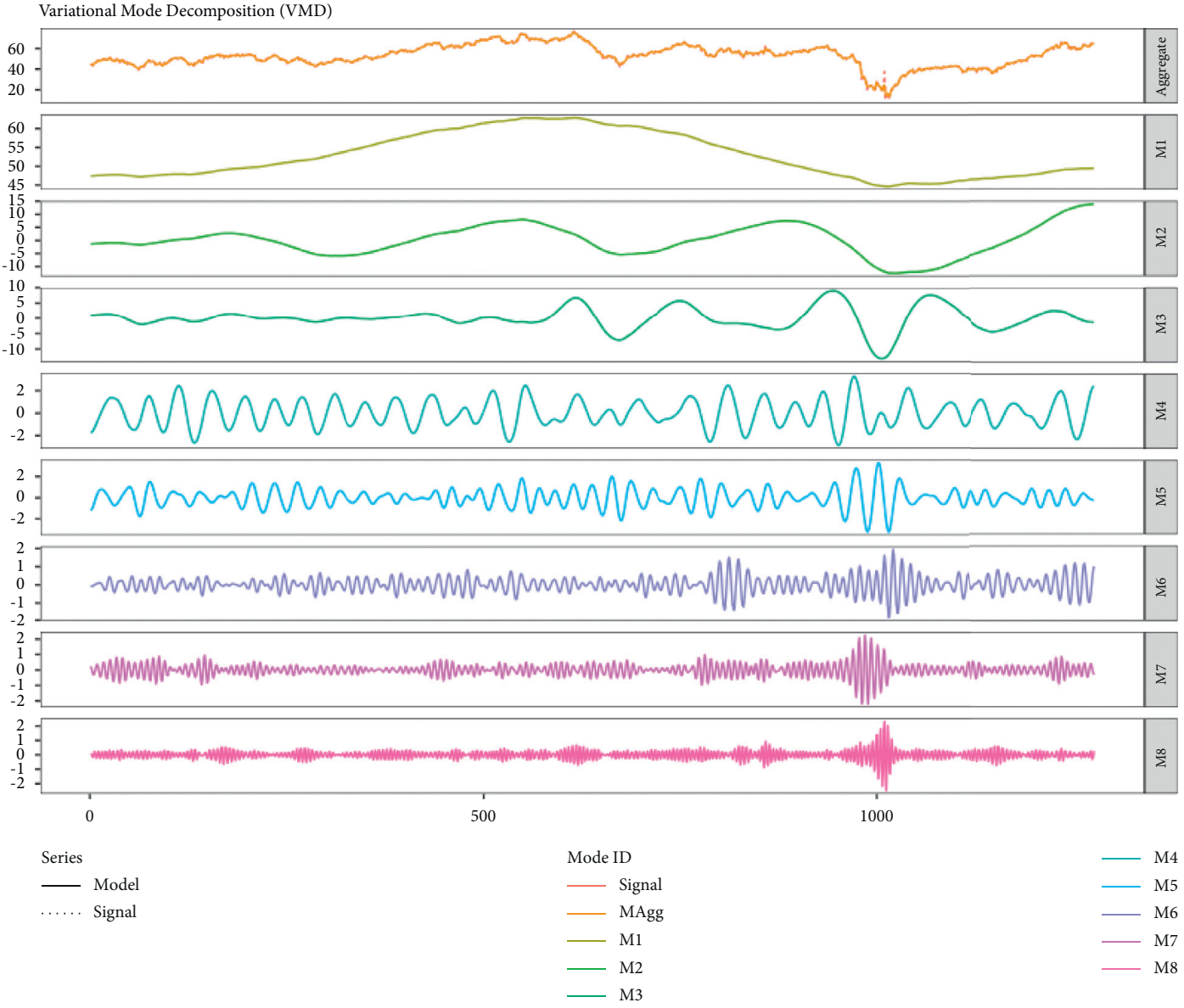

FIGURE 13: Variational mode decomposition curves of daily crude oil price (May 2016-April 2021). 
TABLE 6: Measures of IMFs and residue derived through EMD for Bloomberg daily price series of crude oil (May 2016-April 2021): correlation is significant at the level of 0.05 (2-tailed).

\begin{tabular}{lccccccc}
\hline & $\begin{array}{c}\text { Mean } \\
\text { period }\end{array}$ & $\begin{array}{c}\text { Pearson } \\
\text { correlation }\end{array}$ & $\begin{array}{c}\text { Kendall } \\
\text { correlation }\end{array}$ & $\begin{array}{c}\text { Spearman } \\
\text { correlation }\end{array}$ & Variance & $\begin{array}{c}\text { Variance as of } \\
\text { observed (\%) }\end{array}$ & $\begin{array}{c}\text { Variance as \% of } \\
\text { IMFs + residual (\%) }\end{array}$ \\
\hline $\begin{array}{l}\text { Observed } \\
\text { series }\end{array}$ & 2.00786 & & & & 113.1117 & & \\
IMF1 & 1.60025 & 0.12294 & 0.03922 & 0.05714 & 0.94290 & 0.83360 & 0.89788 \\
IMF2 & 3.50824 & 0.04399 & 0.02738 & 0.03939 & 0.78348 & 0.69266 & 0.74607 \\
IMF3 & 7.73939 & 0.05329 & 0.04523 & 0.06311 & 1.45815 & 1.28912 & 1.38853 \\
IMF4 & 17.98592 & 0.16402 & 0.07260 & 0.10231 & 2.62998 & 2.32512 & 2.50442 \\
IMF5 & 37.55882 & 0.34412 & 0.15764 & 0.22653 & 6.38402 & 5.64400 & 8.07923 \\
IMF6 & 70.94444 & 0.31680 & 0.17563 & 0.26406 & 9.08070 & 8.02808 & 32.64716 \\
IMF7 & 182.42857 & 0.49828 & 0.31549 & 0.47116 & 33.62158 & 29.72423 & 37.69957 \\
IMF8 & 319.25000 & 0.61497 & 0.42600 & 0.60394 & 39.58971 & 35.00054 & 10.02075 \\
Residue & & 0.48211 & 0.46130 & 0.61337 & 10.52316 & 9.30333 & 100.00 \\
Sum & & & & & & 92.84068 & \\
\hline
\end{tabular}

TABle 7: Measures of modes and residue obtained through VMD for Bloomberg daily price series of crude oil (May 2016-April 2021): correlation is significant at the level of 0.05 (2-tailed).

\begin{tabular}{|c|c|c|c|c|c|c|c|}
\hline & $\begin{array}{l}\text { Mean } \\
\text { period }\end{array}$ & $\begin{array}{c}\text { Pearson } \\
\text { correlation }\end{array}$ & $\begin{array}{c}\text { Kendall } \\
\text { correlation }\end{array}$ & $\begin{array}{c}\text { Spearman } \\
\text { correlation }\end{array}$ & Variance & $\begin{array}{c}\text { Variance as of } \\
\text { observed (\%) }\end{array}$ & $\begin{array}{l}\text { Variance as \% of } \\
\sum \text { IMFs + residual }\end{array}$ \\
\hline $\begin{array}{l}\text { Observed } \\
\text { series }\end{array}$ & 2.008 & & & & 113.1117 & & \\
\hline M1 & 21.283 & 0.731 & 0.607 & 0.778 & 34.704 & 30.68 & 42.03 \\
\hline M2 & 49.115 & 0.746 & 0.547 & 0.745 & 32.542 & 28.77 & 39.41 \\
\hline M3 & 55.523 & 0.447 & 0.226 & 0.299 & 12.728 & 11.25 & 15.42 \\
\hline M4 & 21.644 & 0.184 & 0.118 & 0.174 & 1.417 & 1.25 & 1.72 \\
\hline M5 & 13.302 & 0.129 & 0.066 & 0.097 & 0.733 & 0.65 & 0.89 \\
\hline M6 & 5.940 & 0.069 & 0.042 & 0.061 & 0.190 & 0.17 & 0.23 \\
\hline M7 & 3.835 & 0.057 & 0.035 & 0.051 & 0.157 & 0.14 & 0.19 \\
\hline M8 & 2.484 & 0.049 & 0.029 & 0.041 & 0.096 & 0.08 & 0.12 \\
\hline Sum & & & & & & 72.99 & 100 \\
\hline
\end{tabular}

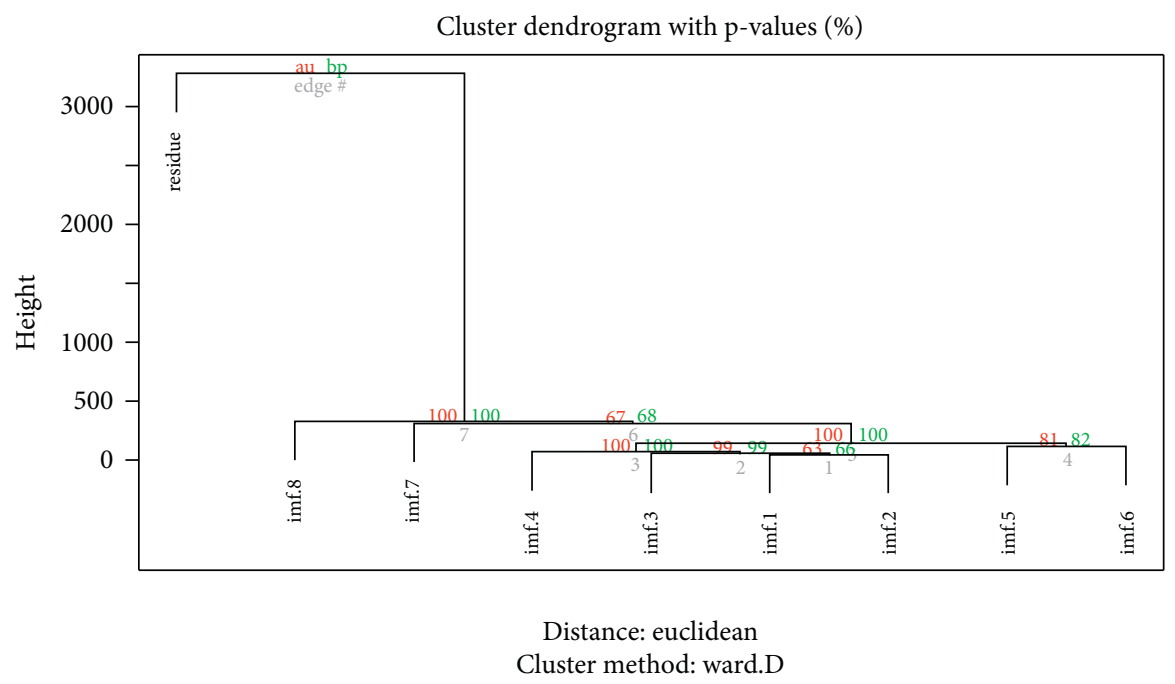

FIgURE 14: Hierarchical clustering diagram obtained for the IMFs and residue through EMD decomposition.

cannot be downplayed in discovering prices of crude oil in the long run, as presented in Table 8. Indeed, the continuing rise in the price of crude oil is in line with worldwide economic growth, and by comparing the trend with the original price series, we can deduce that crude oil prices could fluctuate due to momentous events. The price, however, reverts to trend after the effect of the special event is ended. 
TABLE 8: Correlation and variance of components for Bloomberg daily data of crude oil (May 2016-April 2021) derived through VMD: Correlation is significant at 0.05 level (2-tailed).

\begin{tabular}{|c|c|c|c|c|c|c|c|}
\hline & $\begin{array}{l}\text { Mean } \\
\text { period }\end{array}$ & $\begin{array}{l}\text { Pearson } \\
\text { correlation }\end{array}$ & $\begin{array}{l}\text { Kendall } \\
\text { correlation }\end{array}$ & $\begin{array}{l}\text { Spearman } \\
\text { correlation }\end{array}$ & Variance & $\begin{array}{l}\text { Variance as of } \\
\text { observed }(\%)\end{array}$ & $\begin{array}{c}\text { Variance as \% of } \\
\sum \text { Ms + residual }\end{array}$ \\
\hline $\begin{array}{l}\text { Observed } \\
\text { series }\end{array}$ & & & & & 113.1117 & & \\
\hline $\begin{array}{l}\text { High } \\
\text { frequency }\end{array}$ & 6.353 & 0.203 & 0.086 & 0.117 & 5.802 & 5.129 & 4.608 \\
\hline $\begin{array}{l}\text { Low } \\
\text { frequency }\end{array}$ & 55.522 & 0.929 & 0.765 & 0.928 & 85.413 & 75.512 & 67.832 \\
\hline Trend & 21.283 & 0.731 & 0.607 & 0.778 & 34.704 & 30.681 & 27.561 \\
\hline Sum & & & & & & 111.322 & 100 \\
\hline
\end{tabular}

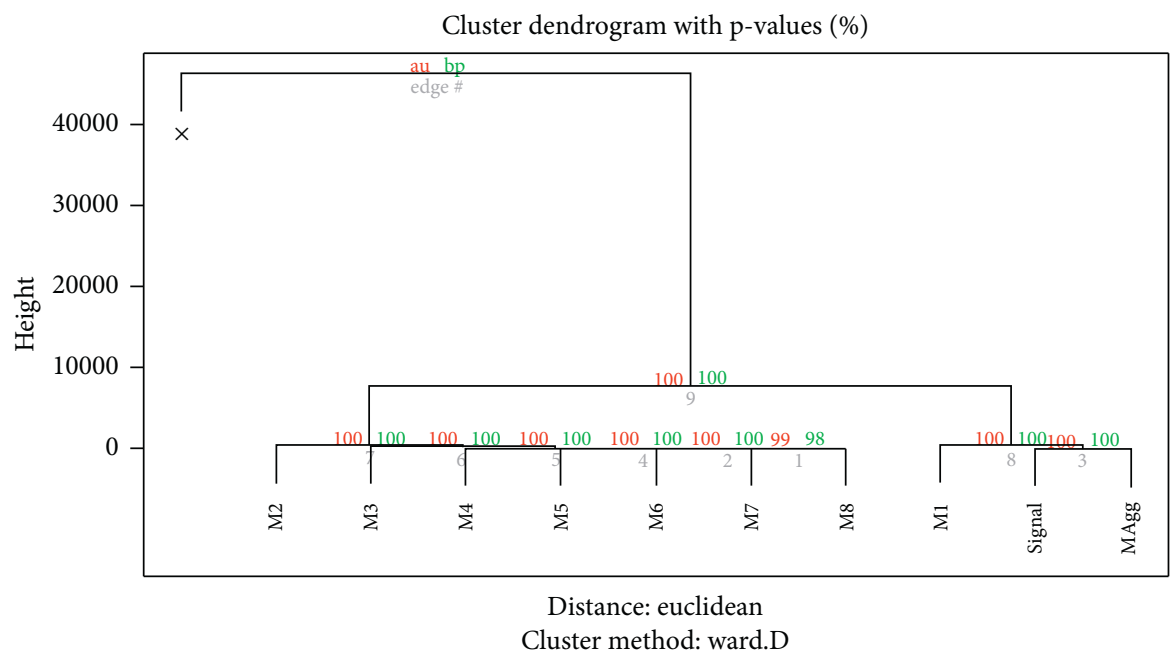

FIGURE 15: Hierarchical clustering diagram obtained from the modes through VMD decomposition.

TABLE 9: Correlation and variance of components obtained from IMFs of EMD for daily price series of crude oil: correlation is significant at 0.05 level (2-tailed).

\begin{tabular}{lccccccc}
\hline & $\begin{array}{c}\text { Mean } \\
\text { period }\end{array}$ & $\begin{array}{c}\text { Pearson } \\
\text { correlation }\end{array}$ & $\begin{array}{c}\text { Kendall } \\
\text { correlation }\end{array}$ & $\begin{array}{c}\text { Spearman } \\
\text { correlation }\end{array}$ & Variance & $\begin{array}{c}\text { Variance as of } \\
\text { observed (\%) }\end{array}$ & $\begin{array}{c}\text { Variance as \% of } \\
\sum \text { IMFs + residual (\%) }\end{array}$ \\
\hline $\begin{array}{l}\text { Observed } \\
\text { series }\end{array}$ & 2.00786 & & & & 113.1117 & & 5.70277 \\
\hline $\begin{array}{l}\text { High } \\
\text { frequency }\end{array}$ & 6.35323 & 0.20288 & 0.08595 & 0.11719 & 5.80187 & 5.12933 & 83.95380 \\
\hline $\begin{array}{l}\text { Low } \\
\text { frequency }\end{array}$ & 55.52174 & 0.92868 & 0.76549 & 0.92792 & 85.41266 & 75.51178 & 10.34342 \\
\hline $\begin{array}{l}\text { Trend } \\
\text { Sum }\end{array}$ & 1277.00000 & 0.4821122 & 0.46130 & 0.61337 & 10.52316 & 9.30333 & 100 \\
\hline
\end{tabular}

5.1.13. Effects of Special Events on Crude Oil Price. Besides the trend, special events are the major contributor of the crude oil price fluctuations. The IMF5-IMF8 and M2 and M3 represent the low-frequency components of decomposition of futures prices of crude oil by EMD and VMD. From EMD, the special events contributed more than $83 \%$ and hold a high correlation coefficient of $0.929,0.765$, and 0.928 between the original price series in terms of Pearson, Kendall, and Spearman, respectively. The low frequency accounted for more than $67 \%$ through VMD of the variance of crude oil price, indicating that the special events were the major component of the wide price swings of crude oil. Interestingly, both EMD and VMD have the same mean period of 55.522 of the low-frequency components, respectively, as presented in Tables 7 and 9, indicate that the period of special events may persist for a more extended period. Examining the mean period of the IMFs and the modes, it takes an average of almost two months for the market to adjust itself to these special events.

Furthermore, the amplitude of some data points could reach a high level of $\$ 15$, indicating that some special events have a remarkable effect on crude oil price determination. 
The medium-term crude oil price fluctuation occurs through special events due to the gradual changes in trend and ordinary market fluctuation that take place at a high frequency. In forecasting, we can estimate every special event, and the results can be used to predict incoming special events of the same nature by isolating special events from the overall price series. Our study conformed to a similar investigation conducted by Zhang et al. [32] on crude oil price analysis using EMD and EEMD methods.

\subsubsection{Effects of Ordinary Market Disequilibrium on Crude} Oil Price. In addition to special events and trends, crude oil prices are also affected by the political situation, atmospheric conditions, inventory exhaustion, and strike actions. The combined effects of these factors constitute the high-frequency component of the crude oil futures price series since their effects are often short. The effect of the ordinary market disequilibrium on the crude oil price is not serious because it takes place at high frequency; thus, considering the amplitudes of the IMFs and modes, their duration is very short. We regarded this element as the consequences of ordinary market disequilibrium and considered it a set of events with near term influence on the crude oil price; we used, shortterm or near term, to describe these effects because the data used in this research is daily. The disequilibrium of supplydemand from ordinary market fluctuation has no serious effect on the crude oil price. These events have frequently occurred and have become one of the major drivers that raise crude oil prices. The ordinary market fluctuations, thus, can be eliminated from the overall series in long-term trend forecasting but they are very crucial for near term prediction; for instance, through the VMD technique, the price of $\$ 64.81$ per barrel in April 2021 can be explicitly explained as a trend price of $\$ 17.86$, a special event price of $\$ 43.96$, and an ordinary market fluctuation of $\$ 2.99$. The three components derived from EMD and VMD methods are presented in Figures 16 and 17, respectively.

5.1.15. Decomposition Results of Gold through EMD and VMD Methods. Likewise, the EMD and VMD techniques were used to break up gold price data into their respective IMFs and modes in this section. The decomposition curves obtained are illustrated in Figures 18 and 19, respectively. The EMD method generated eight decomposed IMFs of gold futures price series, defined as IMF1, IMF2, ..., IMF8, and one residue, as shown in Figure 18, while the VMD approach decomposed the gold series into eight modes. The decomposition result is presented in Figure 19.

5.1.16. Statistics of IMF of Gold Derived through EMD. The residue contributed most to the overall variability of the price series of gold and accounted for over $34 \%$ of the net variance. The correlation coefficients between the residue and the actual price of gold were $0.962,0.559$, and 0.743 in terms of Pearson, Kendall, and Spearman, respectively, as indicated in Table 10. The next significant contributor was IMF7 and accounted for more than $27 \%$ of the observed data variance. The IMF8 contributed more than $13 \%$ of the variance of the observed data with correlation coefficients of 0.285, 0.186, and 0.259 for Pearson, Kendall, and Spearman, in that order. The IMF5, IMF6, and IMF4 accounted for more than $11 \%, 5 \%$, and $4 \%$, respectively, of the total variance of gold price series. These IMFs, IMF4, IMF5, IMF6, IMF7, and IMF8, and residue contributed more than $96 \%$ of the overall variance of the gold futures series. The rest of the IMFs did not contribute much to the total variance of the gold price series, suggesting that the influence of these IMFs on gold price is insignificant.

\subsubsection{Statistics of Mode of Gold through VMD.} Similarly, the VMD method decomposed the price series of gold into eight modes, M1, M2, .., M8, as shown in Figure 19. The dominant mode was M1, which contributed more than $93 \%$ of the total variability of the gold price volatility, with correlation coefficients between the gold price series and the modes of $0.966,0.731$, and 0.902 in terms of Pearson, Kendall, and Spearman, respectively, as presented in Table 11. The next significant contributor to the variability in the gold price was M2, which accounted for $5.420 \%$ of the total variance of the gold futures price series. The correlation coefficients between the observed data and M2 were 0.417 , 0.327 , and 0.427 for Pearson, Kendall, and Spearman, respectively. The M1 and the M2 were considered the two most significant modes, which contributed over $98 \%$ of the entire variability of the volatility of the gold futures series. The contribution of the remaining modes, M3-M8, was less than $2 \%$ of the gold price variance. These modes also showed low correlations' coefficients with the price series of gold, suggesting that their impact on gold price determination is insignificant.

5.1.18. Constitution of Gold Price Series. In this section, we discuss the composition of the gold price in terms of the IMFs and modes' contributions separately. Using the hierarchical clustering and the Euclidean distance between pairs of any two IMFs or modes, the IMFs and the modes were categorized as low frequency, high frequency, and trend. The IMF1-IMF6 formed the high-frequency components of EMD, while IMF7-IMF8 were grouped as the low-frequency components of the gold price series, as shown in Figure 20. These two grouped IMFs and the residue have economic interpretations and provide vital information on gold futures prices. The gradual change of the mean of the residue corresponds to the long-lasting trend of the gold price. The low-frequency component is classified as special events. The effects of short-lived market fluctuations are represented by the high-frequency parts, which can be identified by their shorter amplitudes, as represented in Table 12 and Figure 18.

For VMD, M3-M8 correspond to the high-frequency components of the gold price series and constitute the shortterm effects of normal market fluctuations. M2 represents the low-frequency part of gold futures prices from May 2016 to April 2021 and shows the significant events under study. 


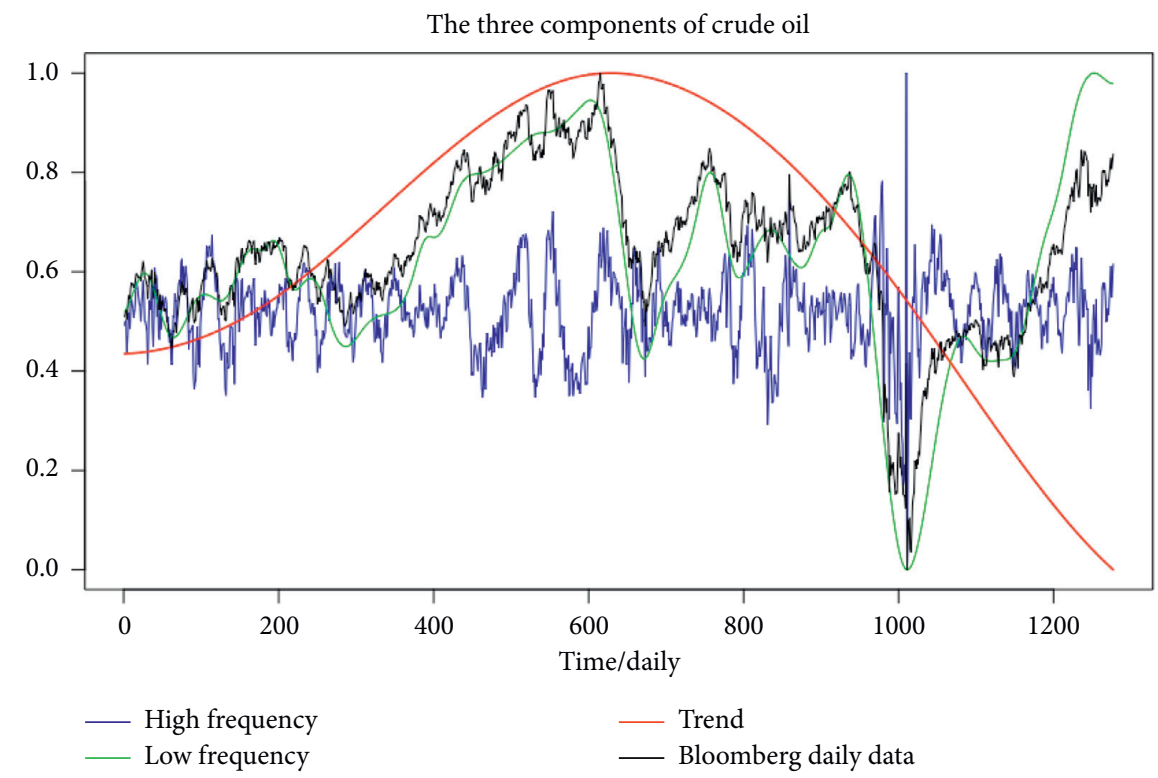

Figure 16: The three components derive from the Bloomberg daily data (May 2016-April 2021) through EMD.

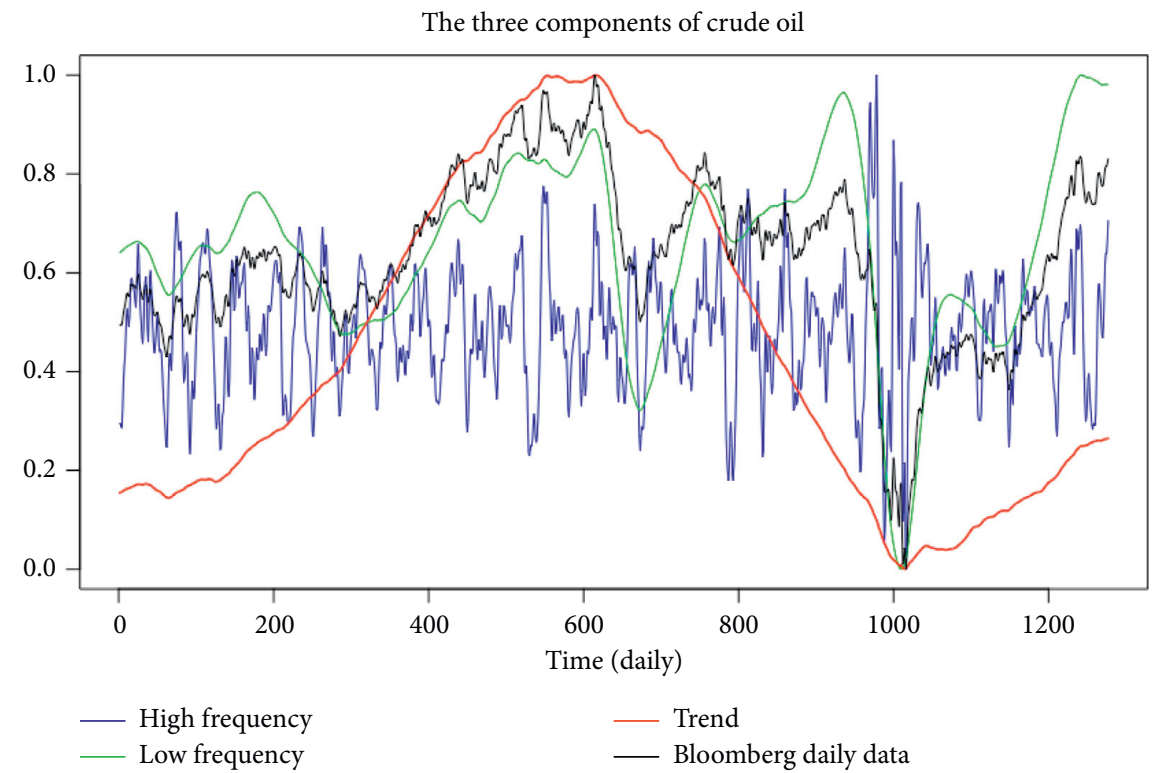

FIgURE 17: The three components derive from the Bloomberg daily data (May 2016-April 2021) through VMD.

The long-term trend of the gold futures prices corresponds to M1, as illustrated in Table 13 and Figure 21.

5.1.19. The Trend of Gold Price Series. Trend contributed more than $91 \%$ and $93 \%$ of the total gold price series variance in EMD and VMD, respectively. It holds the highest correlation coefficient with the observed data, indicating that it is the main force behind the long-term fluctuations of the gold price, as shown in Tables 12 and 13. By comparing the trend with the price series of gold, it demonstrates that, although, gold prices can fluctuate due to special events, but they come back to the trend after the special event is over. Figures 22 and 23 represent the three components of gold futures prices through EMD and VMD, respectively.

5.1.20. Effects of Special Events. The IMF7-IMF8 and M2 represent the low-frequency components of decomposition of futures prices of gold by EMD and VMD, respectively. Low frequency contributed more than $7 \%$ and $5 \%$ of the total variance of the price series of gold for EMD and VMD, while the low frequency constitutes the shock caused by special events of gold price. Based on the average period of the IMFs that constituted the low frequencies, the duration of the shocks takes a minimum of two months for EMD and a minimum of one month and two weeks for VMD; this means 

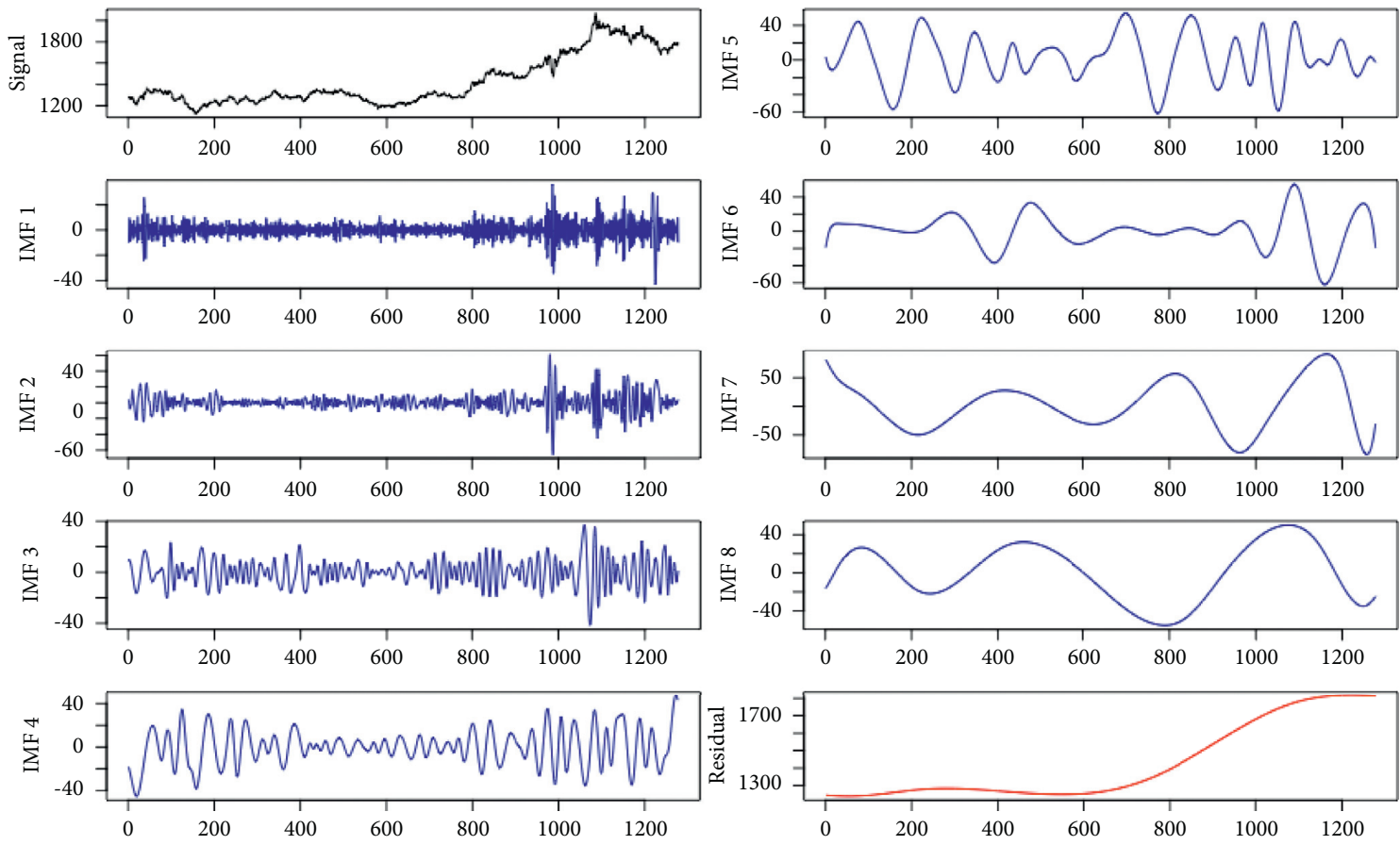

FIGURE 18: Empirical mode decomposition (EMD) curves for the daily gold price series (2008-2019).

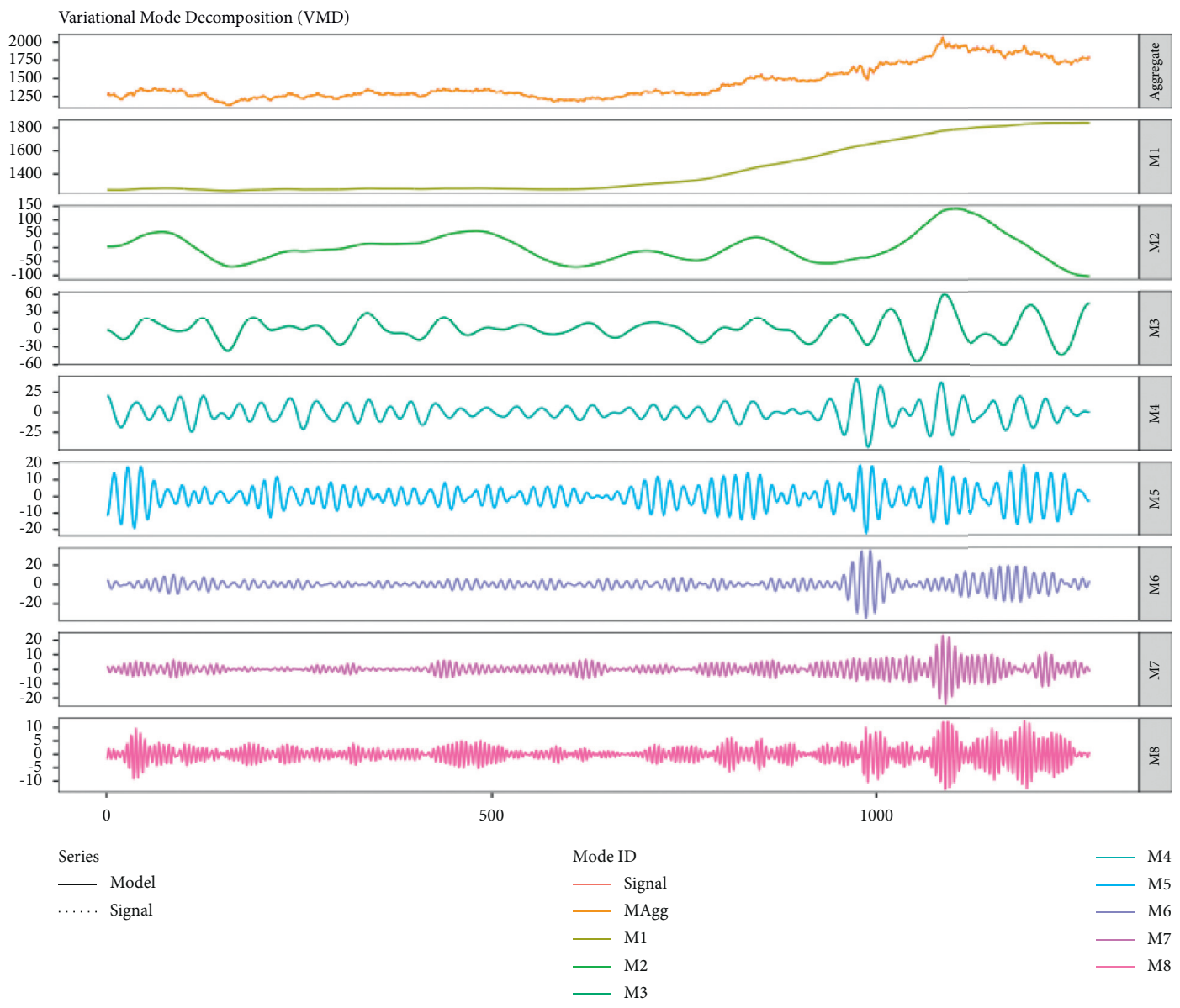

FIGURE 19: Variational mode decomposition (VMD) curves for the daily gold price series (May 2016-April 2021). 
TABLE 10: Measures of IMFs and residue derived through EMD for Bloomberg daily price series of gold (May 2016-April 2021): correlation is significant at the level of 0.05 (2-tailed).

\begin{tabular}{|c|c|c|c|c|c|c|c|}
\hline & $\begin{array}{l}\text { Mean } \\
\text { period }\end{array}$ & $\begin{array}{l}\text { Pearson } \\
\text { correlation }\end{array}$ & $\begin{array}{c}\text { Kendall } \\
\text { correlation }\end{array}$ & $\begin{array}{l}\text { Spearman } \\
\text { correlation }\end{array}$ & Variance & $\begin{array}{l}\text { Variance as of } \\
\text { observed (\%) }\end{array}$ & $\begin{array}{l}\text { Variance as \% of } \\
\text { IMFs + residual }\end{array}$ \\
\hline Observed & 1.912 & & & & 54236.22 & & \\
\hline IMF1 & 1.561 & 0.032 & 0.035 & 0.048 & 52.556 & 0.097 & 0.792 \\
\hline IMF2 & 3.966 & 0.070 & 0.041 & 0.060 & 108.516 & 0.200 & 1.636 \\
\hline IMF3 & 8.513 & 0.057 & 0.052 & 0.072 & 101.769 & 0.188 & 1.534 \\
\hline IMF4 & 19.060 & 0.158 & 0.125 & 0.173 & 267.592 & 0.493 & 4.034 \\
\hline IMF5 & 47.296 & 0.092 & 0.127 & 0.182 & 736.343 & 1.358 & 11.101 \\
\hline IMF6 & 79.813 & -0.030 & 0.087 & 0.113 & 387.337 & 0.714 & 5.834 \\
\hline IMF7 & 182.429 & 0.249 & 0.239 & 0.310 & 1794.455 & 3.309 & 27.053 \\
\hline IMF8 & 212.833 & 0.285 & 0.186 & 0.259 & 876.000 & 1.615 & 13.206 \\
\hline Residue & 319.250 & 0.962 & 0.559 & 0.743 & 2308.628 & 4.257 & 34.804 \\
\hline Sum & & & & & & 12.231 & 100.00 \\
\hline
\end{tabular}

TABLE 11: Measures of modes and residue derived through VMD for Bloomberg daily price series of gold (May 2016-April 2019): correlation is significant at the level of 0.05 (2-tailed).

\begin{tabular}{lccccccc}
\hline & $\begin{array}{c}\text { Mean } \\
\text { period }\end{array}$ & $\begin{array}{c}\text { Pearson } \\
\text { correlation }\end{array}$ & $\begin{array}{c}\text { Kendall } \\
\text { correlation }\end{array}$ & $\begin{array}{c}\text { Spearman } \\
\text { correlation }\end{array}$ & Variance & $\begin{array}{c}\text { Variance as of } \\
\text { observed (\%) }\end{array}$ & $\begin{array}{c}\text { Variance as \% of } \\
\sum \text { IMFs + residual }\end{array}$ \\
\hline Observed & 1.912 & & & & 54236.22 & & \\
M1 & 18.779 & 0.966 & 0.731 & 0.902 & 45806.270 & 84.457 & 93.458 \\
M2 & 44.034 & 0.417 & 0.327 & 0.427 & 2656.298 & 4.898 & 0.658 \\
M3 & 29.698 & 0.142 & 0.123 & 0.152 & 322.526 & 0.595 & 0.249 \\
M4 & 15.202 & 0.075 & 0.080 & 0.113 & 122.172 & 0.225 & 0.089 \\
M5 & 8.457 & 0.059 & 0.038 & 0.054 & 43.413 & 0.080 & 0.076 \\
M6 & 5.626 & 0.047 & 0.040 & 0.051 & 37.134 & 0.068 & 0.031 \\
M7 & 3.917 & 0.029 & 0.025 & 0.033 & 15.249 & 0.028 & 0.020 \\
M8 & 2.929 & 0.024 & 0.021 & 0.029 & 9.602 & 0.018 & 100.00 \\
Sum & & & & & & 92.196 & \\
\hline
\end{tabular}

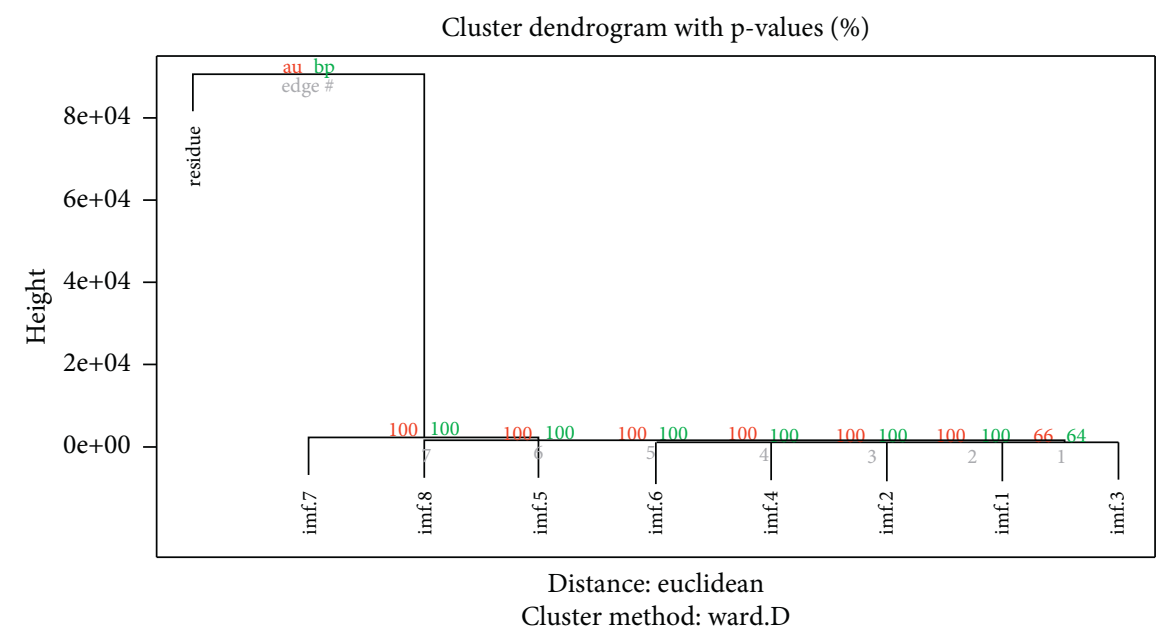

FIGURE 20: Hierarchical clustering diagram obtained for the IMFs and residue of gold through EMD.

that it is difficult for the market to adjust itself to the effects of these special events. The time frame of the effects of special events was longer, which suggests that most special events have a serious impact on the gold price; hence, intermittent fluctuations in gold prices arise through special events.

5.1.21. Effects of Ordinary Market Disequilibrium. Apart from special events and trends, the price of gold is also influenced by political situations, bad weather conditions, industrial action, and inventory depletion. The combined effects of these conditions are classified as high frequency. The effect has a short-term impact on gold price because the time frames of some of these conditions are very short, which suggest that the market disequilibrium has no serious impact on the price of gold. The disequilibrium of supplydemand as a normal market fluctuation, thus, has no serious impact on the gold price. On the one hand, if these events are 
TABLE 12: Correlation and variance of components for Bloomberg daily data of gold from May 2016-April 2021 derived through EMD: correlation is significant at 0.05 level (2-tailed).

\begin{tabular}{|c|c|c|c|c|c|c|c|}
\hline & $\begin{array}{l}\text { Mean } \\
\text { period }\end{array}$ & $\begin{array}{c}\text { Pearson } \\
\text { correlation }\end{array}$ & $\begin{array}{c}\text { Kendall } \\
\text { correlation }\end{array}$ & $\begin{array}{c}\text { Spearman } \\
\text { correlation }\end{array}$ & Variance & $\begin{array}{l}\text { Variance as of } \\
\text { observed }(\%)\end{array}$ & $\begin{array}{l}\text { Variance as \% of } \\
\sum \text { IMFs + residual }\end{array}$ \\
\hline Observed & 1.912 & & & & 54236.22 & & \\
\hline $\begin{array}{l}\text { High } \\
\text { frequency }\end{array}$ & 4.080 & 0.095 & 0.064 & 0.089 & 264.376 & 0.487 & 0.520 \\
\hline $\begin{array}{l}\text { Low } \\
\text { frequency }\end{array}$ & 67.211 & 0.375 & 0.334 & 0.423 & 3913.372 & 7.215 & 7.690 \\
\hline Trend & 319.250 & 0.962 & 0.559 & 0.743 & 46709.450 & 86.122 & 91.790 \\
\hline Sum & & & & & & 93.824 & 100 \\
\hline
\end{tabular}

TABLE 13: Correlation and variance of constituents for daily series of gold (May 2016-April 2021) derived through VMD: correlation is significant at 0.05 level (2-tailed).

\begin{tabular}{|c|c|c|c|c|c|c|c|}
\hline & $\begin{array}{l}\text { Mean } \\
\text { period }\end{array}$ & $\begin{array}{l}\text { Pearson } \\
\text { correlation }\end{array}$ & $\begin{array}{l}\text { Kendall } \\
\text { correlation }\end{array}$ & $\begin{array}{c}\text { Spearman } \\
\text { correlation }\end{array}$ & Variance & $\begin{array}{l}\text { Variance as of } \\
\text { observed (\%) }\end{array}$ & $\begin{array}{l}\text { Variance as \% of } \\
\sum \mathrm{Ms}+\text { residual }\end{array}$ \\
\hline Observed & 1.912 & & & & 54236.22 & & \\
\hline $\begin{array}{l}\text { High } \\
\text { frequency }\end{array}$ & 5.149 & 0.161 & 0.165 & 0.217 & 649.378 & 1.197 & 1.322 \\
\hline $\begin{array}{l}\text { Low } \\
\text { frequency }\end{array}$ & 44.034 & 0.417 & 0.327 & 0.427 & 2656.298 & 4.898 & 5.409 \\
\hline Trend & 18.779 & 0.966 & 0.731 & 0.902 & 45806.270 & 84.457 & 93.269 \\
\hline Sum & & & & & & 90.552 & 100.00 \\
\hline
\end{tabular}

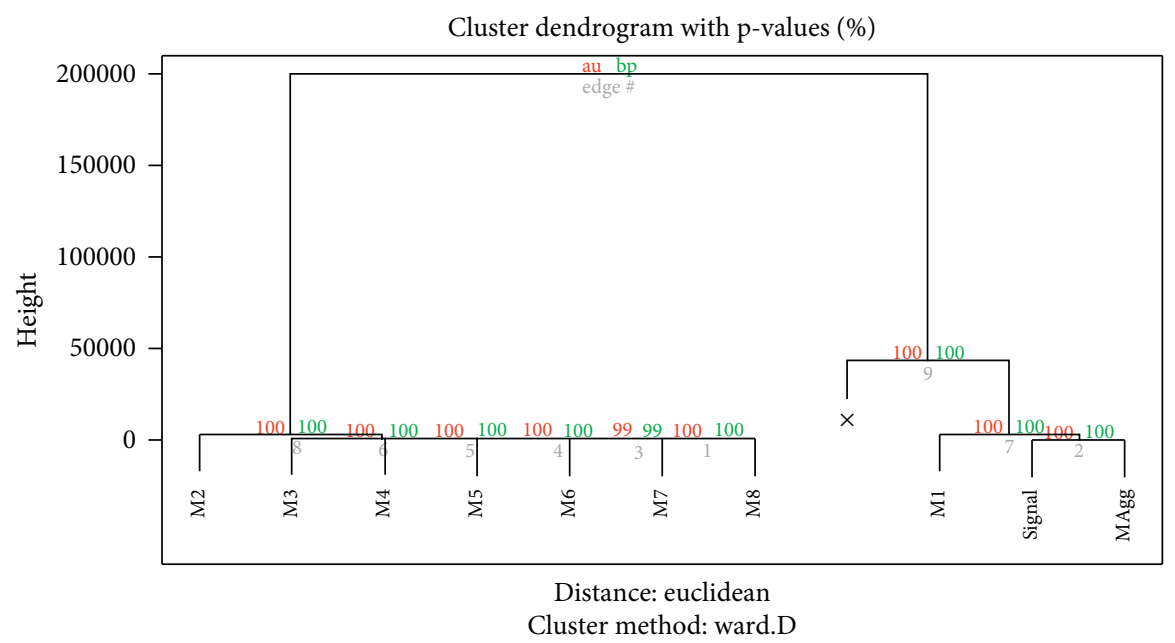

Figure 21: Hierarchical clustering diagram obtained for the modes and residue through VMD.

not checked for a long period, they become one of the major drivers for increasing gold prices. In long-range trend forecasting, the ordinary market fluctuations can be set aside, but crucial for short period prediction.

In a nutshell, gold price composes of the trend (which contributes most of gold price variations in the long period), the special events (which were the leading causes of sporadic price increases of gold in the medium term), and the ordinary market fluxes (with short-lived effects on the gold price). Using the VMD approach, the price of $\$ 1254.23$ per ounce during April 2021 can be analyzed as a trend price of $\$ 1169.81$, a special event price of $\$ 67.84$, and a normal market fluctuation $\$ 16.58$, as shown in Figure 23. 
The three components of gold

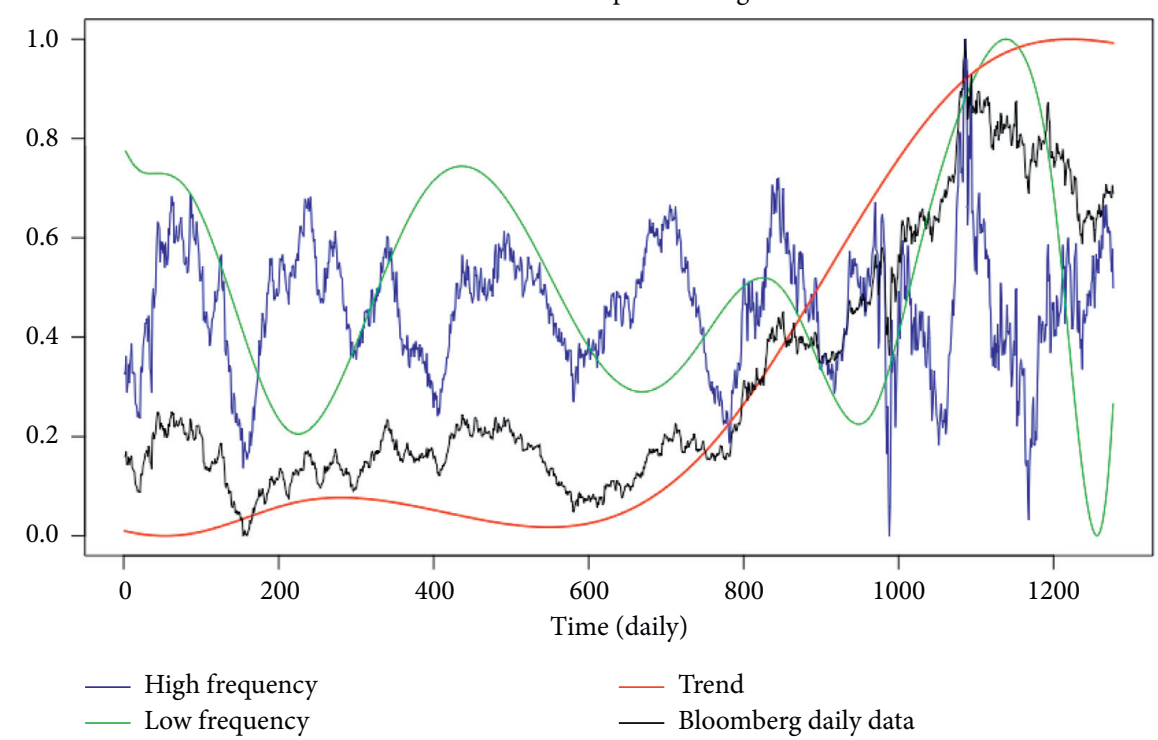

Figure 22: The three components of the Bloomberg daily data (May 2016-April 2021) through EMD.

The three components of gold

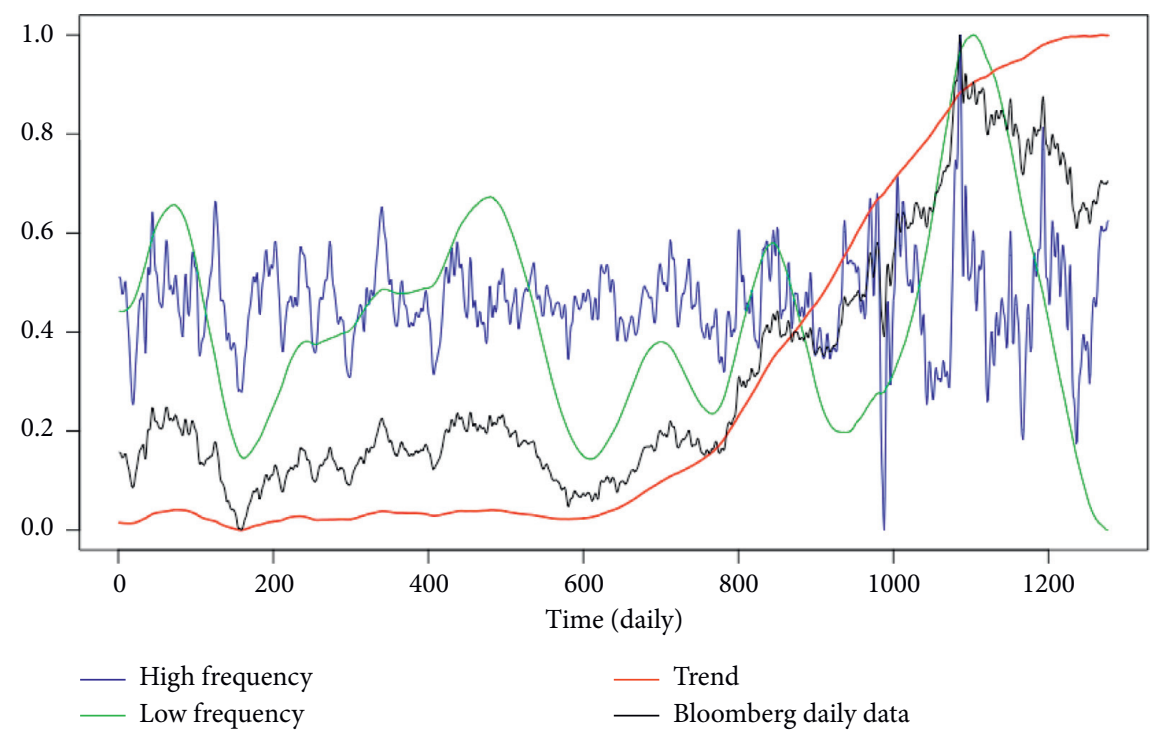

FIgURE 23: The three components of the Bloomberg daily data (May 2016-April 2021) through VMD.

\section{Conclusion}

A new model is proposed to study the underlying factors that causes crude oil, corn, and gold markets price fluctuations based on EMD and VMD techniques. EMD and VMD methods are used to decompose daily closing prices of corn, crude, and gold obtained from Bloomberg Commodity Index from May 2016 to April 2021 into their respective IMFs or modes and a residue to determine the components that derived commodity futures market prices.

Using the Pearson product-moment correlation coefficient, Kendall rank correlation, and Spearman rank correlation as statistical measures enabled us to evaluate each IMF's effects or mode on the commodity futures prices.
Subsequently, we used hierarchical clustering and the Euclidean distance approach to classify the IMFs, residue, and modes into high frequency, low frequency, and trend components, with the trend and low-frequency components being the main drivers of commodity futures prices. The three commodities' prices could be analyzed as a combination of long-term trend, special events, and near term fluctuations resulting from usual market activities, such as imbalance of supply-demand. In general, the three commodities prices are driven by trends and special events. The effects from the trend deviates gradually and changes around the long-term mean. The unpredictable special events are responsible for irregular commodity price movements, and the effect could last for several years; this shows that the 
short-term commodity price changes are mainly triggered by normal market activities, and the effects have a very short duration; hence, their impact on commodity price is not serious.

Essentially, in using the decomposition approach in analyzing components of commodity prices' data series explicitly, several forecasting techniques can be considered: firstly, depending on the characteristics of each IMF or mode, an appropriate forecasting method can be chosen to predict every IMF or mode; for instance, a polynomial function can be used to estimate the residue and Fourier analysis to predict low-frequency IMFs' modes, using a nonlinear method to stimulate high-frequency IMFs or modes and summing them up to obtain the final results. Secondly, the IMFs or modes can be categorized as linear and nonlinear components which can be forecasted separately and then integrating the individual parts to obtain the final predicted results; for instance, the trend can be dealt with using curve fitting, using nonlinear forecasting techniques such as the backpropagation neural network to forecast short-term fluctuations. Special events are difficult to predict since they are influenced by several elements, such as trade wars, outbreak of pandemic, atmospheric conditions, financial policies, and many other sophisticated factors.

Finally, we suggest that a new framework or integrated forecasting method should be developed to handle special events' effects on prices since no one knows when and where they will happen.

\section{Data Availability}

Data can be found at http://www.bloomberg.com.

\section{Additional Points}

Highlights. (i) We investigate futures prices of the following commodities: crude oil, corn, and gold. (ii) We propose a novel price determinant for these commodities: crude oil, corn, and gold. (iii) Empirical mode decomposition and variational mode decomposition are used to decompose crude oil, corn, and gold prices into different components. (iv) We examine the effects of each component on the market price fluctuations. (v) We indicate that empirical mode decomposition and variational mode decomposition can bring out the underlying factors of commodity market price volatility.

\section{Conflicts of Interest}

The authors declare that they have no conflicts of interest.

\section{References}

[1] D. Zhang, G. Zang, J. Li, K. Ma, and H. Liu, "Prediction of soybean price in China using QR-RBF neural network model," Computers and Electronics in Agriculture, vol. 154, pp. 10-17, 2018.
[2] W. Wang and L. Wei, "Impacts of agricultural price support policy on price variability and welfare: evidence from China's soybean market," Agricultural Economics, vol. 52, no. 1, pp. 3-17, 2021.

[3] L. Zhao, X. Zhang, S. Wang, and S. Xu, "The effects of oil price shocks on output and inflation in China," Energy Economics, vol. 53, pp. 101-110, 2016.

[4] H. F. Zou, G. P. Xia, F. T. Yang, and H. Y. Wang, "An investigation and comparison of artificial neural network and time series models for Chinese food grain price forecasting," Neurocomputing, vol. 70, no. 16-18, pp. 2913-292, 2007.

[5] Q. Zhu, F. Zhang, S. Liu, Y. Wu, and L. Wang, "A hybrid VMD-BiGRU model for rubber futures time series forecasting," Applied Soft Computing, vol. 84, Article ID 105739, 2019.

[6] T. Jin, H. Ding, B. Li, H. Xia, and C. Xue, "Valuation of interest rate ceiling and floor based on the uncertain fractional differential equation in Caputo sense," Journal of Intelligent \& Fuzzy Systems, vol. 40, no. 3, pp. 5197-5206, 2021.

[7] P. Sadorsky, "Time-varying risk premiums in petroleum futures prices," Energy Economics, vol. 24, no. 6, pp. 539-556, 2002.

[8] C. Morana, "A semiparametric approach to short-term oil price forecasting," Energy Economics, vol. 23, no. 3, pp. 325-338, 2001.

[9] S. Mirmirani and H. C. Li, "A comparison of VAR and neural networks with genetic algorithm in forecasting price of oil," Advances in Econometrics, vol. 19, pp. 203-223, 2004.

[10] R. Bacon, "Modelling the price of oil," Oxford Review of Economic Policy, vol. 7, no. 2, pp. 17-34, 1991.

[11] S. Dées, P. Karadeloglou, R. K. Kaufmann, and M. Sánchez, "Modelling the world oil market: assessment of a quarterly econometric model," Energy Policy, vol. 35, no. 1, pp. 178-191, 2007.

[12] B. Zhu, P. Wang, J. Chevallier, and Y. Wei, "Carbon price analysis using empirical mode decomposition," Computational Economics, vol. 45, no. 2, pp. 195-206, 2015.

[13] D. Wang, C. Yue, S. Wei, and J. Lv, "Performance analysis of four decomposition-ensemble models for one-day-ahead agricultural commodity futures price forecasting," Algorithms, vol. 10, no. 3, p. 108, 2017.

[14] H. Miao, S. Ramchander, T. Wang, and D. Yang, "Influential factors in crude oil price forecasting," Energy Economics, vol. 68, pp. 77-88, 2017.

[15] H. Boubaker and S. A. Raza, "A wavelet analysis of mean and volatility spillovers between oil and BRICS stock markets," Energy Economics, vol. 64, pp. 105-117, 2017.

[16] J. Wang and X. Li, "A combined neural network model for commodity price forecasting with SSA," Soft Computing, vol. 22, no. 16, pp. 5323-5333, 2018.

[17] N. E. Huang, Z. Shen, S. R. Long et al., "The empirical mode decomposition and the Hilbert spectrum for nonlinear and non-stationary time series analysis," Proceedings of the Royal Society of London. Series A: Mathematical, Physical and Engineering Sciences, vol. 454, no. 1971, pp. 903-995, 1998.

[18] K. Dragomiretskiy and D. Zosso, "Variational mode decomposition," IEEE Transactions on Signal Processing, vol. 62, no. 3, pp. 531-544, 2014.

[19] S. Abadan and A. Shabri, "Hybrid empirical mode decomposition-ARIMA for forecasting price of rice," Applied Mathematical Sciences, vol. 8, no. 63, pp. 3133-3143, 2014.

[20] T. Xiong, C. Li, Y. Bao, Z. Hu, and L. Zhang, "A combination method for interval forecasting of agricultural commodity 
futures prices," Knowledge-Based Systems, vol. 77, pp. 92-102, 2015.

[21] N. An, W. Zhao, J. Wang, D. Shang, and E. Zhao, "Using multi-output feedforward neural network with empirical mode decomposition based signal filtering for electricity demand forecasting," Energy, vol. 49, pp. 279-288, 2013.

[22] L. Crosato, L. Grossi, and F. Nan, "Forecasting the volatility of electricity prices by robust estimation: an application to the Italian market," in Mathematical and Statistical Methods for Actuarial Sciences and Finance, pp. 279-283, Springer, Cham, Switzerland, 2018.

[23] C.-S. Lin, S.-H. Chiu, and T.-Y. Lin, "Empirical mode decomposition-based least squares support vector regression for foreign exchange rate forecasting," Economic Modelling, vol. 29, no. 6, pp. 2583-2590, 2012.

[24] B. Premanode and C. Toumazou, "Improving prediction of exchange rates using differential EMD," Expert Systems with Applications, vol. 40, no. 1, pp. 377-384, 2013.

[25] V. Plakandaras, T. Papadimitriou, and P. Gogas, "Forecasting daily and monthly exchange rates with machine learning techniques," Journal of Forecasting, vol. 34, no. 7, pp. 560-573, 2015.

[26] Y. Jian-Hui and D. Wei, "Prediction of gold price based on WT-SVR and EMD-SVR model," in Proceedings of the 2012 8th International Conference on Computational Intelligence and Security, Guangzhou, China, 2012.

[27] Q. Hua and T. Jiang, "The prediction for London gold price: improved empirical mode decomposition," Applied Economics Letters, vol. 22, no. 17, pp. 1404-1408, 2015.

[28] P. Owusu Junior, A. M. Adam, and G. Tweneboah, "Connectedness of cryptocurrencies and gold returns: evidence from frequency-dependent quantile regressions," Cogent Economics \& Finance, vol. 8, no. 1, Article ID 1804037, 2020.

[29] J. Meng, H. Nie, B. Mo, and Y. Jiang, "Risk spillover effects from global crude oil market to China's commodity sectors," Energy, vol. 202, Article ID 117208, 2020.

[30] H. Chen, H. Liao, B.-J. Tang, and Y.-M. Wei, "Impacts of OPEC's political risk on the international crude oil prices: an empirical analysis based on the SVAR models," Energy Economics, vol. 57, pp. 42-49, 2016.

[31] L. Yu, S. Wang, and K. K. Lai, "Forecasting crude oil price with an EMD-based neural network ensemble learning paradigm," Energy Economics, vol. 30, no. 5, pp. 2623-2635, 2008.

[32] X. Zhang, K. K. Lai, and S.-Y. Wang, "A new approach for crude oil price analysis based on empirical mode decomposition," Energy Economics, vol. 30, no. 3, pp. 905-918, 2008.

[33] Z. Wu and N. E. Huang, "Ensemble empirical mode decomposition: a noise-assisted data analysis method," Advances in Adaptive Data Analysis, vol. 1, no. 1, pp. 1-41, 2009.

[34] V. Korotin, M. Dolgonosov, V. Popov, O. Korotina, and I. Korolkova, "The Ukrainian crisis, economic sanctions, oil shock and commodity currency: analysis based on EMD approach," Research in International Business and Finance, vol. 48, pp. 156-168, 2019.

[35] Y. Zhu, D. Xu, J. Cheng, and S. H. Ali, "Estimating the impact of China's export policy on tin prices: a mode decomposition counterfactual analysis method," Resources Policy, vol. 59, pp. 250-264, 2018.

[36] B. Zhu, L. Huang, L. Yuan, S. Ye, and P. Wang, "Exploring the risk spillover effects between carbon market and electricity market: a bidimensional empirical mode decomposition based conditional value at risk approach," International Review of Economics \& Finance, vol. 67, pp. 163-175, 2020.
[37] S. Lahmiri, “A variational mode decomposition approach for analysis and forecasting of economic and financial time series," Expert Systems with Applications, vol. 55, pp. 268-273, 2016.

[38] C. Aneesh, S. Kumar, P. M. Hisham, and K. P. Soman, "Performance comparison of variational mode decomposition over empirical wavelet transform for the classification of power quality disturbances using support vector machine," Procedia Computer Science, vol. 46, pp. 372-380, 2015.

[39] Y. Seo, S. Kim, and V. Singh, "Machine learning models coupled with variational mode decomposition: a new approach for modeling daily rainfall-runoff," Atmosphere, vol. 9, no. 7, p. 251, 2018.

[40] H. Niu, K. Xu, and W. Wang, "A hybrid stock price index forecasting model based on variational mode decomposition and LSTM network," Applied Intelligence, vol. 50, no. 12, pp. 4296-4309, 2020.

[41] Y. Huang and Y. Deng, "A new crude oil price forecasting model based on variational mode decomposition," Knowledge-Based Systems, vol. 213, Article ID 106669, 2021.

[42] E. Jianwei, J. Ye, and H. Jin, "A novel hybrid model on the prediction of time series and its application for the gold price analysis and forecasting," Physica A: Statistical Mechanics and Its Applications, vol. 527, Article ID 121454, 2019.

[43] K. He, G. K. F. Tso, Y. Zou, and J. Liu, "Crude oil risk forecasting: new evidence from multiscale analysis approach," Energy Economics, vol. 76, pp. 574-583, 2018.

[44] I. Daubechies, Ten Lectures on Wavelets, Society for Industrial and Applied Mathematics, Philadelphia, PA, USA, 1992.

[45] N. Pustelnik, P. Borgnat, and P. Flandrin, "Empirical mode decomposition revisited by multicomponent non-smooth convex optimization," Signal Processing, vol. 102, pp. 313-331, 2014.

[46] I. Daubechies, J. Lu, and H.-T. Wu, "Synchrosqueezed wavelet transforms: an empirical mode decomposition-like tool," Applied and Computational Harmonic Analysis, vol. 30, no. 2, pp. 243-261, 2011.

[47] J. Gilles, "Empirical wavelet transform," IEEE Transactions on Signal Processing, vol. 61, no. 16, pp. 3999-4010, 2013.

[48] M. C. Peel, G. E. Amirthanathan, G. G. S. Pegram, T. A. McMahon, and F. H. S. Chiew, "Issues with the application of empirical mode decomposition," in Proceedings of the 2005 International Congress on Modelling and Simulation, Melbourne, Australia, 2005. 